\title{
Application areas of 3D bioprinting
}

\author{
Ibrahim T. Ozbolat ${ }^{1,2,{ }^{*}}$, Weijie Peng ${ }^{1,2,3}$ and Veli Ozbolat ${ }^{4}$ \\ ${ }^{1}$ Engineering Science and Mechanics Department, The Pennsylvania State University, State College, PA 16802, USA \\ ${ }^{2}$ The Huck Institutes of the Life Sciences, The Pennsylvania State University, State College, PA 16802, USA \\ ${ }^{3}$ Department of Pharmacology, Nanchang University, Nanchang, JX 330006, China \\ ${ }^{4}$ Mechanical Engineering Department, Ceyhan Engineering Faculty, Cukurova University, 01330 Adana, Turkey
}

*Corresponding author: Ozbolat, I.T. (ito1@psu.edu).

Keywords: Bioprinting; tissue engineering; regenerative medicine; transplantation; drug screening; highthroughput screening; cancer research.

Teaser: Bioprinting is a powerful technology in the fabrication of living tissues and organs for tissue engineering and regenerative medicine, transplantation and clinics, pharmaceutics and high-throughput screening, as well as cancer research. 
Three dimensional (3D) bioprinting has been a powerful tool in patterning and precisely placing biologics, including living cells, nucleic acids, drug particles, proteins and growth factors, to recapitulate tissue anatomy, biology and physiology. Since the first time of cytoscribing cells demonstrated in 1986, bioprinting has made a substantial leap forward, particularly in the past 10 years, and it has been widely used in fabrication of living tissues for various application areas. The technology has been recently commercialized by a number of emerging businesses, and bioprinters and bioprinted tissues have gained significant interest in medicine and pharmaceutics. This Keynote review presents the bioprinting technology and covers a first-time comprehensive overview of its application areas from tissue engineering and regenerative medicine to pharmaceutics and cancer research. 


\section{Introduction}

Bioprinting is a growing field that makes a revolutionary impact on medical and pharmaceutical sciences, and has gained significant attention worldwide [1]. Bioprinting can be defined as the simultaneous writing of living cells and biomaterials with a prescribed layer-by-layer stacking organization using a computer-aided transfer process for fabrication of bioengineered constructs [2]. It offers great precision on spatial placement of cells, proteins, DNA, drug particles, growth factors and biologically active particles to guide tissue generation and formation better. This powerful technology appears to be more promising for advancing tissue fabrication toward physiologically relevant tissue constructs, tissue models, tissues and organs and organs-on-a-chip models for medicine and pharmaceutics.

Bioprinting technology has a broad utility in various application areas such as tissue engineering and regenerative medicine $[3,4]$, transplantation and clinics [1], drug screening and high-throughput assays [5] and cancer research [6], as depicted in Figure 1. Bioprinting for tissue engineering and regenerative medicine fields has been around for more than a decade, and anatomically correct cellladen constructs and scaffolds have been fabricated for various tissue types from connective and epithelial tissues to muscle and nervous tissues. With its great advantage in patterning and precisely positioning multiple cell types, bioprinting has circumvented one of the major shortcomings of traditional scaffold fabrication techniques and has enabled fabrication of native-like tissues with a heterocellular microenvironment. Although the vast majority of the effort has been geared toward the fundamental science behind major bioprinting techniques such as laser-, droplet- and extrusion-based bioprinting, a substantial focus has recently been given to bioprinting for functional tissue fabrication [1]. Particularly, considerable work has been dedicated to bioprinting for transplantation, where bioprinted tissues have been implanted to various associated sites in vivo. As further progress takes place in biomaterials, cell and transplantation technologies, bioprinting will translate from bench to 
bedside when approved for human use and has a myriad of advantages in operating rooms in the near future. Before transitioning into clinical practice, bioprinting has already made a great leap in pharmaceutical use because it does not entail any regulatory approvals and there is currently an emerging bioprinting market for tissue fabrication for drug testing and high-throughput assays. With the inclusion of multiple cell types and facilitating a complex heterocellular physiological environment, bioprinted tissue models (e.g. liver) have been used in drug screening. In addition, bioprinting has recently been used in cancer research to investigate cancer pathology, growth and metastasis in a physiologically relevant microenvironment [7]. Here, we present a critical and comprehensive review of the application areas of bioprinting technology and provide an in-depth discussion on successfully bioprinted tissue types in tissue engineering and regenerative medicine, transplantation and clinics, drug screening and high-throughput assays, and cancer research. For each application area, limitations of existing technologies are discussed and future prospects are provided to the reader.

\section{Tissue engineering and regenerative medicine}

Bioprinting of functional organs at clinically relevant dimensions remains elusive because there are several challenges such as but not limited to integration of the vascular network from arteries and veins down to capillaries, incorporation of various cell types to recapitulate complex organ biology and limited structural and mechanical integrity and long-term functionality [8]. Despite these difficulties, a wide variety of tissues have been successfully bioprinted such as thin or hollow tissues, for example blood vessel [9], or tissues that do not need vascularization such as cartilage [1].

\section{Bone tissue}

Bone tissue engineering has been widely studied using bioprinting because bioprinting has the ability to fabricate anatomically correct patient-specific tissue constructs. In a recent study [10], Gao et al. used a thermal inkjet bioprinter to fabricate poly(ethylene glycol) dimethacrylate (PEGDMA) 
scaffolds. Bone-marrow-derived human mesenchymal stem cells (hMSCs) were co-printed with nanoparticles of bioactive glass and hydroxyapatite $(\mathrm{HA})$ under simultaneous polymerization. Bioprinting in that study enabled uniform distribution of hMSCs compared with manually pipetted hMSCs, which accumulated at the bottom of the scaffold because of gravity (Figure 2a). The bioprinted constructs encapsulating hMSCs and HA demonstrated the highest cell viability, collagen production and alkaline phosphate activity with increased compressive modulus after 21-day culture in vitro. Bioprinting HA particles were also performed for in situ bioprinting purposes, where a laser-based bioprinting system was used to deposit HA nanoparticles into mouse calvarial defects in a framework study [11], as detailed below.

In another study, Fedorovich et al. bioprinted heterocellular tissue constructs made of Matrigel $^{\mathrm{TM}}$ and alginate hydrogels [12]. Endothelial progenitor and multipotent stromal cells were bioprinted in a spatially controlled manner and the bioprinted constructs were subcutaneously implanted into immune-deficient mice. By incorporating osteoinductive biphasic calcium phosphate microparticles, multipotent stromal cells were differentiated into an osteogenic lineage and facilitated bone formation in six weeks. In addition to osteoinductive materials, incorporation of growth factors is also crucial in stem cell differentiation in bone tissue engineering. Phillippi et al. demonstrated the effect of bone morphogenetic protein (BMP)-2 on stem cell fate [13]. Using inkjet bioprinting of patterned BMP-2 on fibrin-coated coverslips, primary-muscle-derived stem cells were differentiated toward osteogenic lineage on the pattern even if they were treated with myogenic differentiation conditions.

\section{Cardiac tissue}

Cardiac tissue engineering has been a growing interest because heart failure is a devastating disease [14]. Although myocardium tissue has a limited regeneration capability because myocyte proliferation rapidly ceases after birth [15], tissue engineering of such a structurally and functionally complicated organ is essential. In the literature, limited attempts have been made in bioprinting of 
cardiac tissue models. Jakab et al. demonstrated extrusion-based bioprinting of tissue spheroids comprising human vascular endothelial cells (HUVECs) and cardiac cells isolated from myocardial tubes of chicken embryos [16]. Tissue spheroids that were adhesive and scaffold-free, and possessed rapid self-assembly capabilities, were bioprinted next to each other on collagen type-I biopaper in a singlelayer grid pattern. Upon bioprinting, tissue spheroids were fused together in approximately $70 \mathrm{~h}$ and formed a single cardiac tissue patch that could synchronously beat. In addition to the scaffold-free approach undertaken in the above work, scaffold-based bioprinting has been investigated in a few remarkable studies. Xu et al. bioprinted a cardiac tissue construct in a half-heart shape with connected ventricles using inkjet-based bioprinting (Figure $2 \mathrm{~b} 1, \mathrm{~b} 2$ ) [17]. In their study, primary feline adult and $\mathrm{H} 1$ cardiomyocytes were encapsulated in alginate-gelation composite hydrogels and the crosslinker (calcium chloride solution) was selectively sprayed layer by layer. The resulting tissue construct with connected ventricles was electrically stimulated and functional excitation-contraction coupling was successfully demonstrated. In addition to these studies, patterning of cells was also applied in cardiac tissue engineering. Gaebel et al. utilized laser-induced forward-transfer (LIFT) to pattern HUVECs and hMSCs in a geometrically defined pattern on polyester urethane urea and the fabricated samples were transplanted to the infarcted zone of rat hearts after LAD ligation [18]. In 8 weeks post-transplantation, samples with LIFT-derived patterns facilitated increased vessel formation compared with randomly bioprinted cells as control groups and the resulted myocardium patch provided significant functional improvement. Besides primary cells, human cardiac-derived cardiomyocyte progenitor cells (hCMPCs) were also bioprinted in a mesh pattern [19]. Bioprinted hCMPCs demonstrated phenotypic properties of cardiac lineage with enhanced expression of early cardiac transcription factors Nkx2.5, Gata-4 and Mef2c.

\section{Cartilage tissue}

Current tissue engineering techniques for cartilage regeneration cannot produce cartilage tissue that is indistinguishable from native tissue [20]. Owing to its great potential for precise spatial and 
temporal deposition of cells and biomaterials with sophisticated patterns, bioprinting has recently gained increasing attention for engineering cartilage tissues that can imitate native tissues with zonally differentiated cells and extracellular matrix (ECM) composition. Laser-based bioprinting of stem-celldifferentiated chondrocytes was attempted by Gruene et al., in which a computer-aided biofabrication technique was used with the assistance of LIFT [21]. They successfully bioprinted porcine-bone-marrowderived mesenchymal stem cells (MSCs) with high viability, and the cells maintained their functionality and differentiation ability into osteogenic and chondrogenic lineages.

Inkjet-based bioprinting has also been used in cartilage tissue engineering as well as for cartilage defect repair. Cui et al. modified an HP desktop printer, where they were able to bioprint human chondrocytes loaded in PEGDMA hydrogel [22]. The bioprinted cartilage construct had mechanical properties and biochemical composition close to native cartilage. Also, by implanting bioprinted cartilage constructs into articular cartilage defects, integration with the native tissue was observed with enhanced interface strength, which improved the quality of the repaired cartilage significantly. In another study using the above experimental setup, the same group fabricated PEG scaffolds (Figure 2c1) and investigated the effect of combined transforming growth factor (TGF)- $\beta 1$ and fibroblast growth factor (FGF)-2 on cell proliferation and differentiation capability, and demonstrated that samples treated with TGF- $\beta 1$ and FGF-2 facilitated the highest glycosaminoglycan (GAG) content [23] and samples without growth factor treatment did not secrete GAG even in 4-week culture (Figure 2c2,c5). Most recently, Xu et al. created a hybrid bioprinting method to fabricate mechanically improved cartilage tissue constructs by combining 3D bioprinting and electrospinning techniques [24]. In that study, electrospinning of polycaprolactone $(\mathrm{PCL})$ fibers together with inkjet bioprinting of rabbit elastic chondrocytes in fibrin-collagen hydrogel was demonstrated. After printing, cell viability was well maintained and fabricated constructs formed cartilage tissues, with improved mechanical properties, in vitro and in vivo. 
In addition to hydrogels used in the abovementioned studies, sodium alginate has been widely used for cartilage tissue bioprinting. Ozbolat et al. demonstrated hybrid bioprinting of chondrocytes loaded in printed alginate filaments in tandem with bioprinting of chondrocyte spheroids to increase the cell density [25]. A multi-arm bioprinter was used to facilitate such a complex hybrid architecture. Using sodium alginate and silver nanoparticles, McAlpine's group [26] successfully printed a bionic ear model, which was composed of chondrocyte-loaded alginate in an ear-shape and a conductive coil with the ability to translate sound waves into digital data. Recently, Markstedt et al. demonstrated mixing alginate with nanocellulose, which has outstanding shear-thinning properties that enabled fabrication of anatomically correct ear and meniscus constructs [27].

Despite the great progress in bioprinting for cartilage tissue regeneration, bioprinting of zonally stratified articular cartilage tissues with different structural, biomechanical and biological properties is still a challenge and further progress is needed to achieve articular cartilage tissue constructs with zonal differentiation including more horizontal and thinner collagen fibers with high cell density in the superficial zone, and relatively vertical and thicker collagen fibers with less cell density in the deeper zones.

\section{Heart valves}

In addition to cardiac tissue engineering, engineering heart valves is also important because heart valves do not possess regeneration capability and dysfunctional heart valves, if the damage or disease is detrimental, need to be replaced by mechanical or biological prosthetic counterparts [28]. Such replacement valves, however, are limited by thrombogenicity and calcification [29]. Despite its crucial role in the cardiovascular system, only a limited amount of work has been carried out in the bioprinting of heart valves. Butcher's group demonstrated the first-time bioprinting of a heart valve [30] using a dual-head bioprinter modified from a Fab@Home printer [31]. In that work, a dual crosslinking mechanism, consisting of ionic and physical crosslinking, was used to print PEG-diacrylate (PEGDA) 
mixed with sodium alginate. After printing, porcine aortic valve interstitial cells (PAVICs) were seeded and cultured for up to 21 days. In their study, anatomically accurate axisymmetric aortic valve geometries, composed of a root wall and tri-leaflets, were demonstrated. Although the first-time presented work does not fall under bioprinting because cells were not involved during the printing process, the group later demonstrated bioprinting of aortic valves using different hydrogels and cell phenotypes. In another study by that group [32], dual-nozzle bioprinting of composite alginate-gelatin hydrogel was performed to fabricate thin hydrogel discs. Aortic root sinus smooth muscle cells (SMCs) and aortic valve interstitial cells (VICs) were spatially bioprinted and samples were incubated for a week. The results revealed a cell viability of $81.4 \pm 3.4 \%$ and $83.2 \pm 4.0 \%$ for SMCs and VICs, respectively. Acellular aortic valve constructs, by contrast, exhibited reduced modulus, ultimate strength and peak strain. In a recent study [33], the same group presented bioprinting of composite hydrogels using methacrylated hyaluronic acid (Me-HA) and methacrylated gelatin (Me-Gel) loaded with human aortic valvular interstitial cells (HAVICs). Fabricated samples (Figure 2d1) represented the designed tri-leaflet valve-shape meticulously and the cells bioprinted with increased Me-Gel concentration exhibited better spreading. Human aortic valvular interstitial cells encapsulated within the composite hydrogel expressed alpha smooth muscle actin ( $\alpha$-SMC) and vimentin (Figure $2 \mathrm{~d} 2$ ), and remodeled the ECM by depositing collagen and GAGs.

\section{Liver tissue}

Although liver has excellent regenerative and recuperative properties, liver tissue engineering has been a growing interest because liver failure, in association with failure of multiple organs, is a significant cause of morbidity and mortality [34]. Engineering liver tissues stands as a promising direction for future organ transplantation needs in addition to the great potential of bioprinted liver tissue models in drug testing and high-throughput screening because liver tissue is highly sensitive to drug toxicity. Faulkner-Jones et al. demonstrated the first-time bioprinting of human-induced pluripotent stem cells (hiPSCs), where bioprinted hiPSCs were stimulated and differentiated into 
hepatocytes for liver micro-organ engineering [35]. The presented work systematically analyzed the effect of the bioprinting process on stem cell fate, and the influence of pressure and nozzle length on the viability of hiPSCs and human embryonic stem cells (hESCs), and concluded that the utilized inkjet bioprinting process was gentle enough to maintain viability and pluripotency of cells, and directed their differentiation into a hepatic lineage. A dual-head valve-based inkjet bioprinter was used to deposit sodium alginate and calcium chloride to fabricate multilayer tissue constructs (Figure 2e1) and the results demonstrated that bioprinted stem cells differentiated into a hepatic lineage successfully after a 17-day differentiation period and expressed hepatocyte markers including HNF4 $\alpha$, albumin and ZO-1, where albumin secretion peaked on day 21 (Figure 2e2).

In addition to bioprinting liver tissue constructs, liver carcinoma HepG2 immortal cells were bioprinted in larger tissue models. Bertassoni et al. utilized a modified NovoGen MMX Bioprinter ${ }^{\mathrm{TM}}$ and bioprinted HepG2 cells and fibroblasts within gelatin-methacrylamide (GelMA) hydrogel strands along with agarose strands. Upon printing, agarose solidified immediately as a result of a rapid drop in the temperature and UV light was applied to photo-crosslink GelMA precursor under $6.9 \mathrm{~mW} / \mathrm{cm}^{2}$ of UV light (360-480 nm) for up to $1 \mathrm{~min}$ [36]. After complete gelation of GelMA, agarose was completely removed to create perfusable channels. The study revealed that cells preserved their viability for up to 8 days. The work was then extended using other hydrogels such as star poly(ethylene glycol-co-lactide) acrylate (SPELA), PEGDMA and PEGDA hydrogels at different concentrations [37]. This section presents liver tissue bioprinting attempts for tissue engineering only and further discussion on bioprinting of liver tissue models for drug testing and high-throughput screening will be provided below.

\section{Lung tissue}

Bioprinting for lung tissue engineering is new and there is only one recent attempt studying the fabrication of a lung tissue model using bioprinting. Hovath et al. demonstrated bioprinting of an in vitro air-blood barrier model using BioFactory ${ }^{\circledR}$ by regenHU [38]. In this regard, they bioprinted a zonally 
stratified tissue construct in a few layers. First, a thin layer of Matrigel ${ }^{\mathrm{TM}}$ was bioprinted as a basement membrane followed by bioprinting of a single layer of EA.hy926 endothelial cells to facilitate attachment of cells on the Matrigel ${ }^{\mathrm{TM}}$ layer. Later, on day 2, a new layer of Matrigel ${ }^{\mathrm{TM}}$ was bioprinted on top of the previously built construct followed by bioprinting of a single layer of A549 epithelial cells. Manually deposited layers were also constructed as control samples. On day 5, the samples were fixed for characterization, and cell viability of $>95 \%$ and $\geq 86 \%$ was achieved for epithelial and endothelial cells, respectively. As can be seen in Figure $2 \mathrm{f} 1$ and Figure $2 \mathrm{f3}$, epithelial and endothelial cells were uniformly distributed with epithelial cells on the top and endothelial cells at the bottom. Sagittal histological sections also confirmed formation of thin, packed and uniform tissue layers (Figure 2f2) compared with manually pipetted control samples. The barrier quality, such as the tightness of the constructs, was investigated through measuring the translocation of blue dextran molecules from the apical to the basolateral compartment of the samples after 3 days of culture and results revealed that the tightness of the bioprinted samples was better than that of the manually pipetted samples.

\section{Neural tissue}

Engineering nervous system tissues offers tremendous promise to replace diseased, aged or injured components of nervous system; however, there is limited work done in the context of bioprinting for neural tissue fabrication. Lee et al. studied the effect of vascular endothelial growth factor (VEGF) release on proliferation and migration of murine neural stem cells (C17.2) [39]. In their study, C17.2 cells were bioprinted on a collagen layer next to a fibrin disk loaded with VEGF. The study showed that neural cells migrated toward VEGF-releasing fibrin gel and proliferated successfully in contrast to the cells that could not proliferate within the collagen matrix. Recently, Hsieh et al. demonstrated bioprinting of a thermoresponsive polyurethane hydrogel with tunable stiffness and gelation ability at $37^{\circ} \mathrm{C}$ without the need for a crosslinker [40]. They showed the effectiveness of the bioink by loading it with neural stem cells and injecting it into a zebrafish embryo neural injury model. The results revealed that the injected gel rescued the function of the impaired nervous system in 6 days. 
Owens et al. used a scaffold-free approach, where a pellet of Schwann cells (SCs) and bone marrow stem cells (BMSCs) were extruded within a 3D-printed agarose mold [41] (see Figure 2g1 for the schematic of the process). Cells in the agarose mold aggregated and formed a nerve tissue graft with three lumina in each as shown in Figure $2 \mathrm{~g} 2$. The fabricated grafts were then implanted into mice, and their histology (Figure $2 \mathrm{~g} 3, \mathrm{~g} 4$ ) and functionality was evaluated 10 months after implantation, and compared to the functionality of autologous grafts and hollow collagen grafts. Although the number of samples were not enough to draw a definitive conclusion about the performance of the 3D bioprinted grafts with respect to commercially available collagen grafts, the presented case demonstrated a proofof-concept for bioprinting nerve grafts.

\section{Pancreas tissue}

Because primary pancreatic $\beta$-cells do not easily survive in vitro and only a very few attempts have taken place to differentiate $\beta$-cells from human stem cells, regeneration of pancreas tissue is primarily embodied to the extent that $\beta$-cells from mouse lines or insulinoma cells have been used to fabricate pancreatic islets [42]. A limited amount of work has been done in the context of bioprinting for pancreatic tissue fabrication. Recently, Marchioli et al. encapsulated human and mouse islets as well as rat insulinoma INS1E $\beta$-cells within alginate or alginate-gelatin hydrogels and bioprinted them in duallayer scaffolds [43]. The scaffolds were later implanted in diabetic mice and explanted 7 days thereafter. Although the viability and morphology of islets was not impaired by encapsulation and bioprinting processes in alginate and alginate-gelatin hydrogels (Figure $2 \mathrm{~h}$ ), bioprinted islets and INS1E $\beta$-cells lost their functionality in 7 days because they were not responsive to the change in glucose level. This can be attributed to the high level of calcium $\left(\mathrm{Ca}^{2+}\right)$ ions within crosslinked alginate because transmembrane calcium ion-gradient, mediated by voltage-gated calcium channels, stimulated higher insulin secretion at low glucose level [44]. In addition, recent work demonstrated the microfabrication of scaffold-free tissue strands (with strong expression of insulin) for extrusion-based bioprinting [45], where tissue 
strands were made of rat fibroblasts and mouse insulinoma TC-3 $\beta$-cells in the core and shell, respectively. The authors envisioned to use the demonstrated tissue strands for scale-up tissue bioprinting purposes.

\section{Skin tissue}

A myriad of tissue engineering approaches have been applied in skin tissue fabrication and tissue substitutes including autologous split-thickness skin graft (gold standard) [46], allografts [47], acellular dermal substitutes and cellularized graft-like commercial products [47] [i.e. Dermagraft ${ }^{\circledR}$ and Apligraf $^{\oplus}$ (Organogenesis)] [48]. Recently, bioprinting technology has been adopted for skin tissue fabrication as well. Lee et al. presented bioprinting of skin tissue using an eight-channel valve-based bioprinter, where a 13-layer-tissue construct was bioprinted using collagen hydrogel [49]. Keratinocytes were bioprinted on top of alternating layers of human foreskin fibroblasts and acellular collagen layers, and the resulted constructs demonstrated densely packed cells in epidermis layers as opposed to the dermis with low density of cells and less ECM deposition. In addition to droplet-based bioprinting, laserbased bioprinting has also been used for biofabrication of skin tissue substitutes [50]. Cells from a human immortalized keratinocyte cell line and NIH 3 T3 fibroblasts were bioprinted in collagen matrix in alternating layers on a sheet of Matriderm ${ }^{\mathrm{TM}}$. Histological results demonstrated high density of keratinocytes and fibroblasts with expression of laminin protein, which is a major component of basement membrane in skin. The same group extended their work [51] and demonstrated implantation of the tissue constructs on dorsa of mice as shown in Figure 2i1. Results revealed that the bioprinted tissues were engrafted with the hosts in 11 days (Figure 2i2) with stratified epidermis with early signs of differentiation and formation of the stratum corneum as well as some blood vessels. Control samples at the air-liquid interface in in vitro culture, by contrast, demonstrated proliferation of cells with limited differentiation. In a recent study [52], Boland's group demonstrated the effect of bioprinting endothelial cells within skin substitutes on formation of macrovasculature during new tissue remodeling. In this 
regard, they encapsulated neonatal human dermal fibroblasts and epidermal keratinocytes (NHEKs) in collagen, and laid down the dermis layer followed by patterning human dermal microvascular endothelial cells (HMVECs) on the dermis layer of the construct by selectively bioprinting thrombinladen HMVECS on the manually deposited fibrinogen layer. The process was completed by covering the fibrin layer with collagen-laden NHEKs. Then, the fabricated skin substitutes were implanted on the dorsa of mice and compared with commercially available skin substitutes (control). The results revealed that bioprinted HMVECs formed microvessels and the implanted constructs barely generated contraction compared with the control groups. In the abovementioned studies, tissue constructs were bioprinted in vitro and implanted to a host; however, Skardal et al. [53] demonstrated in situ bioprinting of stratified skin substitutes by alternating layers of fibrinogen-collagen and thrombin loaded with amniotic-fluid-derived stem (AFS) cells owing to their lack of immunogenicity. With in situ bioprinting, skin substitutes were 3D bioprinted directly onto full thickness wounds on pigs and recapitulated the native skin more closely than control groups including the bioink loaded with MSCs and acellular hydrogels. Despite the efforts in skin tissue bioprinting, biofabrication of skin substitutes that virtually mimic native skin is still a challenge because integrating sweat glands and hair follicles has remained elusive [54].

\section{Vascular tissue}

Bioprinting of scale-up tissues and organs vitally depends on vascularization because integration of vascular network will essentially provide oxygen and media supply to cells for their survival and function [2]. Vascular tissue fabrication has been performed by various bioprinting modalities including extrusion- [55-58], droplet- [59,60] and laser-based bioprinting [61]. In extrusion-based bioprinting, a wide variety of extrusion techniques have been utilized. Ozbolat and co-workers used coaxial-nozzle extrusion, where hydrogels including sodium alginate and chitosan were bioprinted directly in tubular form with encapsulated cells $[55,57]$. During co-axial (core-shell) flow, ejected crosslinker (flowing 
through the core) contacted the precursor hydrogel solution (flowing through the shell), and facilitated rapid gelation and formation of tubular constructs (Figure 2j1). Six-week cultured HUMSMC-laden samples demonstrated deposition of smooth muscle matrix (Figure $2 \mathrm{j} 2$ ). That approach enabled direct bioprinting of vascular constructs in a practical manner. In addition, there are other direct vascular tissue bioprinting approaches, such as bioprinting droplets of cell-laden hydrogels layer-by-layer using inkjet-based bioprinting performed by Nakamura and his co-workers [62], Huang's group [59] and Blaeser et al. [60]. Utilizing bottom-up construction, inkjet-based bioprinting enabled branched tubes built in horizontal and vertical directions. A similar approach was also performed using laser-based bioprinting demonstrated by Huang's group [61]. In the abovementioned studies, scaffold-based approaches were utilized; however, Forgacs and co-workers followed a scaffold-free approach in bioprinting vascular tissues, where tissue spheroids were bioprinted one by one and self-assembled into larger tissue units [58]. Because agarose is inert to cell adhesion, the printed agarose mold facilitated rapid fusion of tissue spheroids and maturation of the tissue. In addition to direct bioprinting of tubular vascular tissues, indirect bioprinting of perfusable tissue constructs has been performed using various hydrogels including fibrin [63], collagen [64] and GelMA [36]. In an indirect approach, a fugitive-ink that is dissolvable or reversibly crosslinkable such as agarose [37], sugar [65], Pluronic ${ }^{\circledR}$ [66] or gelatin [64] - was used to create open channels. Upon removing the fugitive ink, endothelial cells were perfused and glued to create endothelium within open channels [65]. This approach enables bioprinting of highly complex vascular constructs that can be perfused over a long time depending on the degradation profile of the matrix. Although both approaches can be utilized, the former is more appropriate in generating vascular grafts for transplantation and the second is more appropriate for fabrication of perfusable channels for in vitro tissue engineering applications [1].

\section{Composite tissues}


In addition to single tissue types, efforts have been geared toward bioprinting composite tissues to recapitulate the complex biology, anatomy and functionality of organ-level structures. Merceron et al. recently demonstrated fabrication of muscle-tendon units by bioprinting hybrid constructs using a multi-head nozzle assembly [67]. In this regard, PCL and PU were 3D printed to construct a frame to support cellular constructs, where half of the unit was printed using PCL and the other half was printed using PU (Figure 3a1-a4). A composite hydrogel-based bioink, comprising $3 \mathrm{mg} / \mathrm{ml}$ hyaluronic acid, 35 $\mathrm{mg} / \mathrm{ml}$ gelatin and $25 \mathrm{mg} / \mathrm{ml}$ fibrinogen in calcium-fee high-glucose Dulbecco's modified eagle medium (DMEM), was used to 3D bioprint 3T3 fibroblasts and myoblasts into the PCL and PU frames to construct tendon and muscle units, respectively. The results revealed cell viability of $>80 \%$ with differentiated cells at the end of a seven-day culture. The final muscle-tendon units were elastic on the PU-C1C12 muscle section with an elastic modulus of $0.39 \pm 0.05 \mathrm{MPa}$ and stiff on the PCL-3T3 tendon side with an elastic modulus of $46.47 \pm 2.67 \mathrm{MPa}$.

In addition to muscle-tendon units, bioprinting of osteochondral models has been an interest in tissue engineering. Fedovorich et al. demonstrated bioprinting of MSCs and chondrocytes using alginate in a mesh pattern with two different cell types bioprinted within two opposite ends of the scaffold [68]. Mesenchymal stem cells were co-extruded with osteoinductive biphasic calcium phosphate particles, HA and $\beta$-tricalcium phosphate. The bioprinted samples were cultured with a mixture of chondrogenic and osteogenic medium for up to 21 days. The results revealed that bioprinted osteochondral tissue constructs demonstrated differentiated characteristics of cells into osteogenic and chondrogenic lineages along with related ECM deposition in vitro and in vivo. A similar approach was performed by Park et al., where a systematic analysis was performed to understand the effect of native ECM components on the fate of osteoblasts and chondrocytes [69]. They bioprinted osteoblasts in collagen type-I and chondrocytes in hyaluronic acid, and compared the performance of bioprinted osteoblasts and chondrocytes when they were bioprinted in hyaluronic acid and collagen type-I, respectively. 
Fourteen-day culture in vitro suggested that osteochondral tissue regeneration could be successfully attained when the proper hydrogel type was selected. The same group demonstrated another osteochondral model by depositing alginate hydrogel loaded with human chondrocytes and human MG63 osteoblasts within a PCL frame [70]. Osteoblasts and chondrocytes were supplemented with osteogenic and chondrogenic growth factors loaded in hydrogels for differentiation purposes. Another approach was conducted using acoustic-based bioprinting for the same purpose, where bioprinted nanodroplets of MSCs in TGF- $\beta 1$ and BMP-2 patterns (Figure 3b1-b4) resulted in localized differentiation of MSCs toward osteogenic and chondrogenic lineages shown by the gene expression study [71].

In addition to osteochondral models, $\mathrm{Yu}$ et al. demonstrated hybrid bioprinting of macrovascularized stromal tissue, where scaffold-free tissue strands made of fibroblasts were assembled around a perfusable macrovasculature loaded with smooth muscle cells extruded through a co-axial nozzle unit [72]. Tissue strands quickly fused and assembled around the macrovasculature in a week, which can be further scaled-up by extending the macrovascular network.

\section{Other tissue types}

In addition to the presented tissue types, there is some other work at the early fundamental study level for bioprinting of retinal and brain tissues. Lorber et al. presented piezoelectric inkjet bioprinting of retinal ganglion cells (RGCs) and glia, and investigated the effect of bioprinting parameters on the viability of cells and their growth-promoting properties [73]. They concluded that inkjet bioprinting did not adversely affect the cell viability and RGC neurite outgrowth, rather RGCs demonstrated further neurite growth when bioprinted on a glial substrate. Recently, Lozano et al. presented manual deposition of primary cortical neuron-laden gellan-gum-RGD for brain-like tissue fabrication [74]. Three-layer constructed tissue models, with cortical neurons encapsulated in the top and bottom layers, demonstrated axon growth and penetration toward the cell-free middle layer in 5 
days. Although no computer control motion system was applied, the presented work unveiled the first time demonstration of layer-by-layer fabrication for brain tissue engineering.

\section{Transplantation and clinics}

Bioprinting of living tissue and organ constructs has been widely studied and performance of these constructs was assessed via animal transplantation. Several bioprinted tissue types, including nerve [41], cardiac [18], blood vessel [9], bone [11] and skin [52], have been implanted into associated locations on animals to evaluate their functionality, neovascularization and anastomosis and engraftment with the host [1]. In addition, various tissue constructs were bioprinted and implanted subcutaneously to assess in vivo differentiation of cells and functionality of implanted tissue constructs [68]. Despite these attempts, none of the bioprinted tissues has been clinically used for humans because no approval has been granted from the FDA yet. There are no regulations laid down for bioprinters or bioprinted products; however, with the increasing global interest and emerging businesses in the growing bioprinting market, the success with the first technology going through FDA regulations will be exemplary for preceding technologies and products. For details of the regulatory concerns of bioprinting, the reader is referred to our recent article [75].

Although bioprinting technology is still in its infancy in clinics, 3D-printed plastic, ceramic or metallic implants for bone tissue replacement [76] have been successfully transplanted into humans. In addition to permanent implants, a recent work published in New England Journal of Medicine [77] demonstrated a unique case of transplantation of a 3D-printed bioresorbable airway splint into an infant. The institutional review board of the University of Michigan consulted with the FDA and approved the use of a 3D-printed device under the emergency-use exemption and the written consent of the patient's parents. No unforeseen problems have been observed with the splint and full degradation of the device is expected to take around 3 years. This was an exemplary case for clinical use of 3D-printed scaffolds and hopefully will lead to similar success with bioprinted tissues and organs. 
Despite the accomplishments in bioprinting research, bioprinting for transplantation in a clinical setting for humans requires further advances and translational efforts. Organs and tissues that do not need significant vascularization (i.e. skin and cartilage) are expected to be translated into clinical use sooner. Tissues and organs that are metabolically highly active (i.e. heart, pancreas and liver) are immensely challenging. No bioprinting technology so far facilitated the fabrication of a vascular hierarchical network spanning arteries and veins down to capillaries. Because it is difficult to bioprint capillaries at the submicron scale using the current technology, an alternative could be to bioprint macrovasculature and then leave nature to create capillaries by itself. Bioprinted vascular networks should be designed and fabricated in a way that they can be easily sutured to a blood vessel in a host, and possess certain properties such as enough mechanical strength to satisfy burst pressure, sufficient intactness of endothelium to prevent thrombosis and a high patency rate to support occlusion-free circulation [78].

The other approach in facilitating vascularization is in situ bioprinting of tissue and organ constructs directly into the defect sites in surgery settings rather than bioprinting tissue constructs, and maturating and assessing them in vitro before transplantation. With in situ bioprinting, bioprinted tissue constructs can recruit endothelial cells from the host and facilitate neovascularization followed by anastomosis of newly formed vessels with the vascular network of the host. Therefore, in situ bioprinting has a great advantage over the traditional two-step bioprinting approach and can be applied for regeneration of a wide array of tissues and organs (e.g. maxillo- and cranio-facial reconstruction, plastic surgery, skin tissue and flap tissue). In situ bioprinting has been recently used in skin regeneration for large wounds on porcine models [53] and calvarium defects in rodents [1,11]. Figure 5a demonstrates laser-assisted printing of n-HA particles into crucial size defects on a mouse model, where one of the defects remained empty for the control group. The histology and microtomography results for bone regeneration were not consistent (Figure $5 b, c$ ), which was due to immobilization of printed $n$ HA particles within the defects. Although the ink in the demonstrated work did not comprise any 
biologics, it unveiled the application of laser-based bioprinting systems in operating rooms, which will enable translation of bioprinting technologies from bench to bedside.

One of the controversies of the clinical translation potential of bioprinted tissues and organs originates from the bioprinting technology itself because bioprinting involves living cells in bioink and the use of patient-specific cells is fairly new in bioprinting. Stem cells, such as embryonic stem cells and induced-pluripotent stem cells [79], have been potential unlimited sources of patient-specific cells for fabrication of tissues and organs. Patient-specific cells can be differentiated and then bioprinted or bioprinted and then differentiated toward multiple lineages to fabricate tissues and organs that will contribute minimum immunogenicity risk.

\section{Pharmaceutics and high-throughput screening}

Drug discovery entails a time-consuming and costly endeavor that requires substantial investment in financial and human resources. Despite continuing efforts to improve the productivity of the drug development process, only one out of an estimated 10000 new chemical entities and one out of ten drug candidates entering clinical trials reaches the final approval stage and enters the market [80]. Improving the ability to predict the efficacy and toxicity of drug candidates earlier in the drug discovery process will speed up the translation of new drugs into clinics. Recent attempts in 3D in vitro assay systems is an ideal way to resolve this bottleneck because 3D tissue models can closely mimic the native tissue and have the capability to be used in high-throughput assays because they can be fabricated in microarrays. Among various methods for engineering 3D in vitro systems [81], bioprinting has superiorities such as controllability on size and microarchitecture, high-throughput capability, coculture ability and low-risk of cross-contamination. Bioprinted tissue and organ models have been increasingly considered for the potential of pharmaceutics use such as drug toxicology and highthroughput screening [75]. 
In the literature, liver and tumor tissue have been a primary focus in fabrication of tissue models for pharmaceutics. Sun's group investigated the fabrication of a bioprinted liver micro-organ model for drug metabolism [82] (Figure 5a1). In that study, an automated syringe-based direct cell-writing process was applied for extrusion of hepatocyte (HepG2)-encapsulated alginate strands as demonstrated in Figure 5a2. Polydimethylsiloxane (PDMS) elastomer soft lithography was combined with a micromolding technique to fabricate 3D microfluidic chambers housing aforementioned constructs. The presented 3D liver micro-organ with a sinusoidal flow pattern was an in vitro 3D microfluidic, micro-analytical, microorgan (3DM) device for simulation of the physiological liver response to drug administrations and toxic chemical exposure. Effective drug metabolism in the micro-liver chamber was demonstrated by metabolizing a nonfluorescent pro-drug, 7-ethoxy-4-trifluoromethyl coumarin (EFC), to an effluent fluorescent metabolite 7-hydroxy-4-trifluoromethyl coumarin (HFC). Additionally, they schemed and created dual-microtissue microfluidic chips, which were connected to facilitate multicellular interaction and downstream effects of metabolism on the target tissue $[5,83]$. Epithelial cells and hepatocytes encapsulated in Matrige ${ }^{\mathrm{TM}}$ were used to show the path of drug diffusing from the bloodstream to the tissue because epithelial cells are the cells lining the lumen through which the drugs pass from bloodstream to the target, where hepatocytes were used as the target cell type. The anti-radiation drug amifostine was used as a pro-drug, which can be converted to an active form by epithelial cells. The results showed that the percentage of radiation-damaged cells for the single-tissue was more than twice the dual-tissue. Based on the presented tissue model, Tourlomousis and Chang developed a computational macroscale model for such in vitro tissue models using a convection-diffusion-cell kinetics numerical framework, which is helpful for future research in 3D micro-organ pharmacokinetics and toxicity [84].

Emerging microengineering technologies enable versatile fabrication of 3D cell-based microarrays including soft lithography, surface patterning, microfluidic-based manipulation and 
bioprinting [81]. Among them, bioprinting technology has the advantage of generating co-culture and single-cell array with precise control on cell density in a high-throughput manner. A recent study developed a novel inkjet-based bioprinting method for assembling a high-throughput miniature drugscreening platform as presented in Figure 5b1 [85]. The authors applied a modified HP model 5360 compact disc printer with picoliter per droplet resolution and bioprinted Escherichia-coli-laden alginate to array a chip on coverslips (Figure 5b2,b3). Droplets of three antibiotics were printed on the spots of cells in a layer-by-layer fashion. Results demonstrated similar cell viability, functionality and antibacterial effects of antibiotics in inkjet bioprinted and micropipetted samples, which confirmed that inkjetbioprinted high-throughput arrays is an effective method to minimize the duration of typical drug screening tests. Demirci's group presented cell-based biosensors (CBBs), where acoustic-based bioprinting, studied by the same group earlier for high-throughput screening purposes with various cells (including mouse embryonic stem cells, fibroblasts, AML-12 hepatocytes, human Raji cells and HL-1 cardiomyocytes) [86], was used to create a microarray of smooth muscle cell droplets in collagen [87]. The bioprinted microarray was then stimulated with different environmental conditions (e.g. temperature) and the effect of the applied stimuli as well as the bioprinting process parameters on cell viability was evaluated. With the bioprinted CBBs, the effects of analytes, such as pathogens, contaminants, toxins and drug candidates, on living systems can be obtained [87]. Besides 3D bioprinting of high-throughput cell microarrays, controlled delivery of drug candidates into cell microarrays is also a key factor for successful drug screening. Various methods have been developed for controlled drug delivery onto cell microarrays, including drug patterning, drug stamping, aerosol sprays and microfluidic drug loading [81].

Recently, bioprinting companies have developed bioprinted tissue models for high-throughput drug screening $[88,89]$. In November 2014, Organovo began offering its 3D-printed exVive3D ${ }^{\mathrm{TM}}$ liver tissue models to screen drugs for liver toxicity. A scaffold-free tissue bioprinting approach was 
performed using NovoGen MMX Bioprinter ${ }^{\mathrm{TM}}$, where pellets of co-cultured human hepatocytes, hepatic stellate and endothelial cells were bioprinted into a temporary mold structure with building units in a hexagonal shape (Figure 5c1) [90]. After bioprinting, cells further aggregated and the tissue construct matured toward a native-like tissue model (Figure 5c2), which maintains normal function for at least 42 days. Formation of microcapillaries took place at certain locations. The bioprinted tissues were characterized by ATP production and secretion of liver-specific albumin protein. The results revealed that ATP production increased over time during a 4-week culture period and ELISA results showed that albumin secretion increased after fabrication and stabilized in 21 days. One pharmaceutical partner recently employed Organovo to test two of its drugs within the same class. One of the drugs has been used for years and was considered safe; the other failed in a late Phase III clinical trial owing to liver toxicity that did not show up in either cell culture or animal studies. Organovo's system demonstrated very clear signals confirming the commercial drug's safety and the failed drug's toxicity. Other companies, including Aspect Biosystems from Vancouver, Canada, and Texas-based Nano3D Biosciences, are also developing technology for a similar purpose.

\section{Cancer research}

Two-dimensional tumor models have been widely used in cancer research; however, they do not represent the physiologically relevant environment because they lack cell-cell and cell-matrix interactions in 3D. Thus, bioprinting has offered great advantages to recapitulate the cancer microenvironment to precisely locate various cell types and microcapillaries to study cancer pathogenesis and metastasis; however, bioprinting for cancer research is new and only a few research procedures have been performed in this emerging application area [7]. Demirci's group was the first to demonstrate bioprinting of tumor tissue models for in vitro assays [91]. In their study, human ovarian cancer (OVCAR-5) cells and MRC-5 fibroblasts were bioprinted using an inkjet-based bioprinting platform with dual-ejectors. Multiple cell types were spontaneously bioprinted on Matrigel ${ }^{\mathrm{TM}}$ to form multicellular acini in a high-throughput and reproducible manner with a spatially mediated 
microenvironment with controlled cell density and cell-cell distance. The presented approach did not only demonstrate a tool for cancer research but also provided a great platform for high-throughput screening. Sun's group recently demonstrated bioprinting of HeLa cells to form cervical tumor models [92]. In this regard, HeLa cells were extruded and bioprinted in a gelatin-alginate-fibrinogen composite hydrogel in patterned-form with $>90 \%$ cell viability. In 5-8 days, HeLa cells migrated toward each other and formed cell aggregates within hydrogel filaments (Figure 6) as opposed to the control groups, where cells in 2D culture formed cell sheets with lower chemoresistance and lower level expression of metalloproteinase. Although these two studies presented biofabrication of tumor spheroids using bioprinting technology, fabrication of larger tissue models to study cancer cell migration and metastasis is also important. Huang et al. [93] demonstrated a laser-based 3D projection printing system to bioprint HeLa cells and noncancerous $10 \mathrm{~T} 1 / 2$ fibroblasts in PEGDA along with microvascular network with channel widths of 25,45 and $120 \mu \mathrm{m}$ to reflect blood vessel diameters. The results revealed that bioprinted fibroblasts were not affected by the morphology of the channel width; however, HeLa cells migrated significantly when the channel diameter decreased. In addition to scaffold-based approaches, Organovo demonstrated scaffold-free bioprinting of a breast cancer model using the NovoGen Bioprinting ${ }^{\mathrm{TM}}$ platform, where cancer cells were surrounded by a physiologically relevant stromal milieu comprising MSC-differentiated adipose cells, mammary fibroblasts and endothelial cells [94]. Histomorphological analysis revealed that bioprinted neotissues were viable for 2 weeks in vitro with a clear compartmentalization of adipose, stromal and epithelial components with localized signs of microcapillary formation. The effects of the chemotherapeutic drug tamoxifen were assessed for viability by ATP luciferase assay and it was concluded that isolated $2 \mathrm{D}$ cancer cells were more susceptible to tamoxifen-induced toxicity than cells incorporated into 3D tissue models when treated with the same dose of the drug for the same period in vitro. Table 1 summarizes the application areas of bioprinting technology and lists the tissue types that have been successfully bioprinted along with the 
information of cell and bioink types, bioprinting modalities and bioprinters used in fabrication of each tissue type.

\section{Concluding remarks and future outlook}

This paper has introduced bioprinting technology and presented a first-time comprehensive review of its application areas including basic research in tissue engineering, regenerative medicine and cancer pathogenesis, tissue bioprinting for transplantation and clinics, and some recent efforts in beginning translational technologies in pharmaceutics for drug testing and high-throughput screening. Currently, there are around 15 different tissue types under experimentation in the bioprinting field; however, there exist a number of other tissues in the human body that have not been touched yet. In this regard, diverging the focus into other tissue and organ models that are challenging but can revolutionize medicine is necessary in the near future. This also depends on the advances in the tissue engineering field because bioprinting research vitally depends on our understanding of unexplored tissue types. In addition, bioprinting of new types of organs, such as bionic organs or organs that do not exist in nature, will be one of the new directions in bioprinting.

The majority of bioprinting research has evolved around homocellular tissue construct using a single cell type; however, native tissues have a heterocellular nature with multiple cell types patterned in a highly complex anatomy. Although bioprinting-simplified tissue models are relatively acceptable in basic research, functional tissue fabrication for clinics or pharmaceutics necessitates inclusion of multiple cell types because some of the functionality of cells can be enabled or further boosted by cellcell interactions. Bioprinting multiple cell types requires further understanding of the optimum culture conditions including the right medium and reagents to support their growth and behavior.

Current efforts in translation of bioprinting to transplantation are mainly limited to murine models. Murine models are small and physiological conditions of the animals are not closely relevant to that of humans. For example, a small representative pancreatic tissue with bioprinted islets can be 
implanted into a diabetic murine model and can regulate insulin secretion, but the average volume of islets in a mouse pancreas is approximately 100000 times smaller than that in a human pancreas $[95,96]$. Therefore, bioprinting of scale-up tissues and organs is highly important to fabricate them at clinically relevant dimensions. Larger animals such as a porcine model can be a transitional step toward trials on humans because these models represent human physiology more closely than small animals [97]. To scale-up bioprinted organs for clinical use, bioprinting of hierarchical vascular networks is vital in addition to their mechanical strength and elasticity, and long-term structural stability. In addition, integration of nerve tissues and establishing innervation is a vital step toward functional tissue and organ fabrication because tissues such as cardiac, muscle and skin need innervation, which is currently a challenge in bioprinting. The majority of bioprinting research entails the use of hydrogel-based bioinks as a result of their favorable environment for 3D growth of cells [100]; however, hydrogels are weak in mechanical properties when they are used at low concentrations to support cell proliferation. In addition, biodegradable materials such as thermoplastics can be used as a supporting frame for the scale-up of tissues and organs. Current biomaterials using synthetic polymers are strong but their degradation takes a prolonged time and does not match with the tissue regeneration process closely. Therefore, new biomaterial development is crucial for the advancement in bioprinting of tissues and organs for clinical use. In addition to biomaterials, selection of the right cell source is also a crucial factor in translation of bioprinting technologies into clinics and pharmaceutics. For personalized medicine it is challenging to acquire different primary cell types. Stem cells stand as a promising source of cells and further advances are needed to establish standard protocols for differentiation of stem cells into various stable and functional cell lineages.

Miniature 3D-array platforms such as tissue-on-a-chip or organ-on-a-chip models are a prominent way of tissue fabrication for high-throughput screening. Combination of bioprinting technology with other technologies such as microfluidics is needed for fabricating physiologically 
simulated, complex and long-term viable target micro-organ arrays. Technologies generating picoliter droplets with low process induced cell damage with single cell sorting capabilities should be encouraged in bioprinting of cell microarrays. Controlled drug delivery onto cell microarrays should be elaborately considered and implemented.

Despite the recent attempts in engineering cancer microenvironment using bioprinting technology, further advancements are needed for fabrication of a physiologically relevant complete microenvironment, comprising tumor site, healthy site and microvascular network in between, in order to study cancer metastasis research. Tumor tissue models should be precisely placed within bioprinted vascularized parenchymal tissues to study tumor growth, and tumor cell intravasation and extravasation.

\section{Acknowledgments}

This work has been supported by National Science Foundation CMMI Awards 1349716 and 1462232, Diabetes in Action Research and Education Foundation grant \#426 and the China Scholarship Council 201308360128.

\section{References}

1. Ozbolat, I.T. (2015) Bioprinting scale-up tissue and organ constructs for transplantation. Trends Biotechnol. 33, 395-400

2. Ozbolat, I.T. (2015) Scaffold-based or scaffold-free bioprinting: competing or complementing approaches? J. Nanotechnol. Eng. Med. 6, 24701

3. Jakab, K. et al. (2010) Tissue engineering by self-assembly and bio-printing of living cells. Biofabrication 2, 22001

4. Moroni, L. et al. (2006) 3D fiber-deposited scaffolds for tissue engineering: influence of pores geometry and architecture on dynamic mechanical properties. Biomaterials 27, 974-985

5. Snyder, J.E. et al. (2011) Bioprinting cell-laden matrigel for radioprotection study of liver by pro- 
drug conversion in a dual-tissue microfluidic chip. Biofabrication 3, 034112

6. Perkins, J.D. (2007) Are we reporting the same thing? Liver Transpl. 13, 465-466

7. Knowlton, S. et al. (2015) Bioprinting for cancer research. Trends Biotechnol. 33, 504-513

8. Ozbolat, I.T. and Yu, Y. (2013) Bioprinting toward organ fabrication: challenges and future trends. IEEE Trans. Biomed. Eng. 60, 691-699

9. Itoh, M. et al. (2015) Correction: scaffold-free tubular tissues created by a Bio-3D printer undergo remodeling and endothelialization when implanted in rat aortae. PLoS One 10, e 0145971

10. Gao, G. et al. (2014) Bioactive nanoparticles stimulate bone tissue formation in bioprinted threedimensional scaffold and human mesenchymal stem cells. Biotechnol. J. 9, 1304-1311

11. Keriquel, V. et al. (2010) In vivo bioprinting for computer- and robotic-assisted medical intervention: preliminary study in mice. Biofabrication 2, 14101

12. Fedorovich, N.E. et al. (2008) Three-dimensional fiber deposition of cell-laden, viable, patterned constructs for bone tissue printing. Tissue Eng. Part A 14, 127-133

13. Phillippi, J.A. et al. (2008) Microenvironments engineered by inkjet bioprinting spatially direct adult stem cells toward muscle- and bone-like subpopulations. Stem Cells 26, 127-134

14. Hirt, M.N. et al. (2014) Cardiac tissue engineering: state of the art. Circ. Res. 114, 354-367

15. Eulalio, A. et al. (2012) Functional screening identifies miRNAs inducing cardiac regeneration. Nature 492, 376-381

16. Jakab, K. et al. (2008) Tissue engineering by self-assembly of cells printed into topologically defined structures. Tissue Eng. Part A 14, 413-421

17. Xu, T. et al. (2009) Fabrication and characterization of bio-engineered cardiac pseudo tissues. Biofabrication 1, 35001

18. Gaebel, R. et al. (2011) Patterning human stem cells and endothelial cells with laser printing for cardiac regeneration. Biomaterials 32, 9218-9230 
19. Gaetani, R. et al. (2012) Cardiac tissue engineering using tissue printing technology and human cardiac progenitor cells. Biomaterials 33, 1782-1790

20. Makris, E.A. et al. (2015) Repair and tissue engineering techniques for articular cartilage. Nat. Rev. Rheumatol. 11, 21-34

21. Gruene, M. et al. (2010) Laser printing of stem cells for biofabrication of scaffold-free autologous grafts. Tissue Eng. Part C Methods 17, 79-87

22. Cui, X. et al. (2012) Direct human cartilage repair using three-dimensional bioprinting technology. Tissue Eng. Part A 18, 1304-1312

23. Cui, X. et al. (2012) Synergistic action of fibroblast growth factor-2 and transforming growth factor-beta1 enhances bioprinted human neocartilage formation. Biotechnol. Bioeng. 109, 23572368

24. Xu, T.X. et al. (2013) Hybrid printing of mechanically and biologically improved constructs for cartilage tissue engineering applications. Biofabrication 5, 15001

25. Ozbolat, I.T. et al. (2014) Development of 'Multi-arm Bioprinter' for hybrid biofabrication of tissue engineering constructs. Robot. Comput. Integr. Manuf. 30, 295-304

26. Mannoor, M.S. et al. (2013) 3D printed bionic ears. Nano Lett. 13, 2634-2639

27. Markstedt, K. et al. (2015) 3D bioprinting human chondrocytes with nanocellulose-alginate bioink for cartilage tissue engineering applications. Biomacromolecules 16, 1489-1496

28. Hockaday, L.A. et al. (2014) 3D-printed hydrogel technologies for tissue-engineered heart valves. 3D Print. Addit. Manuf. 1, 122-136

29. Jana, S. and Lerman, A. (2015) Bioprinting a cardiac valve. Biotechnol. Adv. 33, 1503-1521

30. Hockaday, L.A. et al. (2012) Rapid 3D printing of anatomically accurate and mechanically heterogeneous aortic valve hydrogel scaffolds. Biofabrication 4, 35005

31. Malone, E. and Lipson, H. (2007) Fab@Home: the personal desktop fabricator kitnull. Rapid 
Prototyp. J. 13, 245-255

32. Duan, B. et al. (2013) 3D bioprinting of heterogeneous aortic valve conduits with alginate/gelatin hydrogels. J. Biomed. Mater. Res. Part A 101A, 1255-1264

33. Duan, B. et al. (2014) Three-dimensional printed trileaflet valve conduits using biological hydrogels and human valve interstitial cells. Acta Biomater. 10, 1836-1846

34. No, D.Y. et al. (2015) 3D liver models on a microplatform: well-defined culture, engineering of liver tissue and liver-on-a-chip. Lab Chip 15, 3822-3837

35. Faulkner-Jones, A. et al. (2015) Bioprinting of human pluripotent stem cells and their directed differentiation into hepatocyte-like cells for the generation of mini-livers in 3D. Biofabrication 7, 44102

36. Bertassoni, L.E. et al. (2014) Direct-write bioprinting of cell-laden methacrylated gelatin hydrogels. Biofabrication 6, 024105

37. Bertassoni, L.E. et al. (2014) Hydrogel bioprinted microchannel networks for vascularization of tissue engineering constructs. Lab Chip 14, 2202-2211

38. Horváth, L. et al. (2015) Engineering an in vitro air-blood barrier by 3D bioprinting. Sci. Rep. 5, 7974

39. Lee, Y-B. et al. (2010) Bio-printing of collagen and VEGF-releasing fibrin gel scaffolds for neural stem cell culture. Exp. Neurol. 223, 645-652

40. Hsieh, F-Y. et al (2015) 3D bioprinting of neural stem cell-laden thermoresponsive biodegradable polyurethane hydrogel and potential in central nervous system repair. Biomaterials $71,48-57$

41. Owens, C.M. et al. (2013) Biofabrication and testing of a fully cellular nerve graft. Biofabrication 5,45007

42. Pagliuca, F.W. et al. (2015) Generation of functional human pancreatic $\beta$ cells in vitro. Cell 159, 428-439 
43. Marchioli, G. (2015) Fabrication of three-dimensional bioplotted hydrogel scaffolds for islets of Langerhans transplantation. Biofabrication 7, 25009

44. Proks, P. and Ashcroft, F.M. (1995) Effects of divalent cations on exocytosis and endocytosis from single mouse pancreatic beta-cells. J. Physiol. 487, 465-477

45. Akkouch, A. et al. (2015) Microfabrication of scaffold-free tissue strands for three-dimensional tissue engineering. Biofabrication 7, 31002

46. Coruh, A. and Yontar, Y. (2012) Application of split-thickness dermal grafts in deep partial- and full-thickness burns: a new source of auto-skin grafting. J. Burn Care Res. 33, e94-100

47. Leon-Villapalos, J. et al. (2010) The use of human deceased donor skin allograft in burn care. Cell Tissue Bank. 11, 99-104

48. Metcalfe, A.D. and Ferguson, M.W.J. (2007) Tissue engineering of replacement skin: the crossroads of biomaterials, wound healing, embryonic development, stem cells and regeneration. J. R. Soc. Interface 4, 413-437

49. Lee, V. et al. (2013) Design and fabrication of human skin by three-dimensional bioprinting. Tissue Eng. Part C Methods 20, 473-484

50. Koch, L. et al. (2012) Skin tissue generation by laser cell printing. Biotechnol. Bioeng. 109, 18551863

51. Michael, S. et al. (2013) Tissue engineered skin substitutes created by laser-assisted bioprinting form skin-like structures in the dorsal skin fold chamber in mice. PLoS One 8, e57741

52. Yanez, M. et al. (2014) In vivo assessment of printed microvasculature in a bilayer skin graft to treat full-thickness wounds. Tissue Eng. Part A 21, 224-233

53. Skardal, A. et al. (2012) Bioprinted amniotic fluid-derived stem cells accelerate healing of large skin wounds. Stem Cells Transl. Med. 1, 792-802

54. Higgins, C.A. et al. (2013) Microenvironmental reprogramming by three-dimensional culture 
enables dermal papilla cells to induce de novo human hair-follicle growth. Proc. Natl. Acad. Sci. U. S. A. $110,19679-19688$

55. Zhang, Y. et al. (2013) Direct bioprinting of vessel-like tubular microfluidic channels. J. Nanotechnol. Eng. Med. 4, 020902

56. Yu, Y. et al. (2013) Evaluation of cell viability and functionality in vessel-like bioprintable cellladen tubular channels. J. Biomech. Eng. 135, 91011

57. Zhang, Y. et al. (2013) Characterization of printable cellular micro-fluidic channels for tissue engineering. Biofabrication 5, 025004

58. Norotte, C. et al. (2009) Scaffold-free vascular tissue engineering using bioprinting. Biomaterials $30,5910-5917$

59. Christensen, K. et al. (2015) Freeform inkjet printing of cellular structures with bifurcations. Biotechnol. Bioeng. 112, 1047-1055

60. Blaeser, A. et al. (2013) Biofabrication under fluorocarbon: a novel freeform fabrication technique to generate high aspect ratio tissue-engineered constructs. Biores. Open Access 2, $374-384$

61. Xiong, R. (2015) Freeform drop-on-demand laser printing of 3D alginate and cellular constructs. Biofabrication 7, 45011

62. Nishiyama, Y. et al. (2008) Development of a three-dimensional bioprinter: construction of cell supporting structures using hydrogel and state-of-the-art inkjet technology. J. Biomech. Eng. 131, 35001

63. Lee, V.K. et al. (2014) Generation of multi-scale vascular network system within 3D hydrogel using 3D bio-printing technology. Cell. Mol. Bioeng. 7, 460-472

64. Zhao, L. et al. (2012) The integration of 3-D cell printing and mesoscopic fluorescence molecular tomography of vascular constructs within thick hydrogel scaffolds. Biomaterials 33, 5325-5332 
65. Miller, J.S. et al. (2012) Rapid casting of patterned vascular networks for perfusable engineered three-dimensional tissues. Nat. Mater. 11, 768-774

66. Wu, W. et al. (2011) Omnidirectional printing of 3D microvascular networks. Adv. Mater. 23, H178-183

67. Merceron, T.K. (2015) 3D bioprinted complex structure for engineering the muscle-tendon unit. Biofabrication 7, 35003

68. Fedorovich, N.E. et al. (2011) Biofabrication of osteochondral tissue equivalents by printing topologically defined, cell-laden hydrogel scaffolds. Tissue Eng. Part C Methods 18, 33-44

69. Park, J.Y. et al. (2014) A comparative study on collagen type I and hyaluronic acid dependent cell behavior for osteochondral tissue bioprinting. Biofabrication 6, 35004

70. Shim, J-H. et al. (2012) Bioprinting of a mechanically enhanced three-dimensional dual cell-laden construct for osteochondral tissue engineering using a multi-head tissue/organ building system. J. Micromechanics Microengineering 22, 85014

71. Gurkan, U.A. et al. (2014) Engineering anisotropic biomimetic fibrocartilage microenvironment by bioprinting mesenchymal stem cells in nanoliter gel droplets. Mol. Pharm. 11, 2151-2159

72. Yu, Y. et al. (2014) A hybrid bioprinting approach for scale-up tissue fabrication. J. Manuf. Sci. Eng. 136, 61013

73. Lorber, B. et al. (2014) Adult rat retinal ganglion cells and glia can be printed by piezoelectric inkjet printing. Biofabrication 6, 15001

74. Lozano, R. et al. (2015) 3D printing of layered brain-like structures using peptide modified gellan gum substrates. Biomaterials 67, 264-273

75. Ozbolat, I.T. and Hospodiuk, M. (2016) Current advances and future perspectives in extrusionbased bioprinting. Biomaterials 76, 321-343

76. Bose, S. et al. (2013) Bone tissue engineering using 3D printing. Mater. Today 16, 496-504 
77. Zopf, D.A. et al. (2013) Bioresorbable airway splint created with a three-dimensional printer. N.

Engl. J. Med. 368, 2043-2045

78. Quint, C. et al. (2011) Decellularized tissue-engineered blood vessel as an arterial conduit. Proc. Natl. Acad. Sci. U. S. A. 108, 9214-9219

79. Yoshida, Y. and Yamanaka, S. (2010) Recent stem cell advances: induced pluripotent stem cells for disease modeling and stem cell-based regeneration. Circ. 122, 80-87

80. Nam, K-H. et al. (2015) Biomimetic 3D tissue models for advanced high-throughput drug screening. J. Lab. Autom. 20, 201-215

81. Xu, F. et al. (2011) Microengineering methods for cell-based microarrays and high-throughput drug-screening applications. Biofabrication 3, 34101

82. Chang, R. et al. (2008) Direct cell writing of 3D microorgan for in vitro pharmacokinetic model. Tissue Eng. Part C Methods 14, 157-166

83. Chang, R. et al. (2010) Biofabrication of a three-dimensional liver micro-organ as an in vitro drug metabolism model. Biofabrication 2, 45004

84. Tourlomousis, F. and Chang, R.C. (2016) Numerical investigation of dynamic microorgan devices as drug screening platforms. Part I: macroscale modeling approach \& validation. Biotechnol. Bioeng. 113, 612-622

85. Rodríguez-Dévora, J.I. et al. (2012) High throughput miniature drug-screening platform using bioprinting technology. Biofabrication 4, 35001

86. Demirci, U. and Montesano, G. (2007) Single cell epitaxy by acoustic picolitre droplets. Lab Chip 7, 1139-1145

87. Xu, F. et al. (2009) Cell bioprinting as a potential high-throughput method for fabricating cellbased biosensors (CBBs). IEEE Sensors doi: 10.1109/ICSENS.2009.5398245

88. Vaidya, M. (2015) Startups tout commercially 3D-printed tissue for drug screening. Nat. Med. 21, 2 
89. Nelson, B. (2015) 3-dimensional bioprinting makes its mark: new tissue and organ printing methods are yielding critical new tools for the laboratory and clinic. Cancer Cytopathol. 123, 203204

90. Roskos, K. et al. (2015) Bioprinting: an industrial perspective. In Essentials of 3D Biofabrication and Translation (Atala, A. and Yoo, J.J., eds), pp. 395-412, Elsevier

91. Xu, F. et al. (2011) A three-dimensional in vitro ovarian cancer coculture model using a highthroughput cell patterning platform. Biotechnol. J. 6, 204-212

92. Zhao, Y. et al. (2014) Three-dimensional printing of Hela cells for cervical tumor model in vitro. Biofabrication 6, 35001

93. Huang, T.Q. et al. (2014) 3D printing of biomimetic microstructures for cancer cell migration. Biomed. Microdevices 16, 127-132

94. King, S.M. et al. (2014) Development of 3D bioprinted human breast cancer for in vitro drug screening. Cancer Res. 74, 2034

95. Bock, T. et al. (2003) Increased islet volume but unchanged islet number in ob/ob mice. Diabetes $52,1716-1722$

96. Ionescu-Tirgoviste, C. et al. (2015) A 3D map of the islet routes throughout the healthy human pancreas. Sci. Rep. 5, 14634

97. Meurens, F. et al. (2012) The pig: a model for human infectious diseases. Trends Microbiol. 20, $50-57$

98. Zhang, Y. et al. (2015) In vitro study of directly bioprinted perfusable vasculature conduits. Biomater. Sci. 3, 134-143.

99. Dolati, F. et al. (2014) In vitro evaluation of carbon-nanotube-reinforced bioprintable vascular conduits. Nanotechnology 25, 145101 
100. Dababneh, A. and Ozbolat, I.T. (2014) Bioprinting technology: a current state-of-the-art review. J. Manuf. Sci. Eng. 136, 061016 


\section{Figure legends}

Figure 1. Application areas of bioprinting technology including tissue engineering and regenerative medicine, transplantation and clinics, drug screening and high-throughput assays, and cancer research (image courtesy of Christopher Barnatt from http://www.explaningthefuture.com).

Figure 2. Bioprinted tissue constructs for tissue engineering and regenerative medicine. (a) Inkjet bioprinting of human mesenchymal stem cells (hMSCs) in hydrogels for bone tissue engineering, where bioprinting resulted in uniform distribution of hMSCs opposed to accumulated hMSCs at the bottom of the scaffold as a result of gravity when hMSCs were manually pipetted; adapted, with permission, from [10]. (b1) Bioprinting of cardiac tissue constructs with connected ventricles using a modified-HP printer, (b2) SEM image of the cross-section of the scaffold showing loaded cells; adapted, with permission, from [17]. (c1) Bioprinting of a $4 \mathrm{~mm}$ poly(ethylene glycol) (PEG) cartilage tissue construct with (c2-c5) Safranin-O staining with limited glycosaminoglycan (GAG) deposition without transforming growth factor (TGF)- $\beta 1$ and fibroblast growth factor (FGF)-2 treatment even if high density (20 million cells per ml) was used; adapted, with permission, from [23]. (d1) A bioprinted heart valve with encapsulated human aortic valvular interstitial cells (HAVICs) and (d2) a representative immunohistochemistry image showing $\alpha$-SMA (green) and vimentin (red) expression; adapted, with permission, from [33]. (e1) A bioprinted 40-layer alginate ring-shape construct, where (e2) hECSc differentiated toward hepatocytelike cells showing positive for albumin expression; adapted, with permission, from [35]. (f1) Bioprinted four-layer lung tissue model with highly organized distribution of a549 cells (green) and endothelial cells (labeled with VE-cadherin in pink), where F-actin and nuclei are labeled in red and white, respectively. (f2) Histological cross-section stained with Masson-Goldner trichrome coloration showing uniform thickness of a tissue sample. Cytoplasm, collagen fibers and cell nuclei are stained in red, green and dark brown, respectively. (f3) Sagittal cross-section demonstrates uniform epithelial layer on the top and endothelial cell layer at the bottom; adapted, with permission, from [38]. (g1) Scaffold-free bioprinting 
of nerve tissue using bone marrow stem cell (BMSC) pellet and co-culture of BMSC and Schwan cell pellet, where cell pellet was bioprinted within printed agarose mold for aggregation of cells (g2) for multi-luminal nerve grafts, $(\mathrm{g} 3, \mathrm{~g} 4)$ Bielschowsky's staining of histological sections showing axons as black dots; adapted, with permission, from [41]. (h) Green fluorescent protein (GFP)-transduced islets plotted in alginate-gelatin scaffolds kept their morphology for over a week in culture compared with the encapsulated counterparts in bulk hydrogels (control); adapted, with permission, from [43]. (i1) A bioprinted skin substitute consisting of 20-layer of fibroblasts and 20-layer of keratinocytes on top of Matriderm ${ }^{\circledR}$ was implanted on the dorsa of a mouse (i2) and resulted in complete wound closure on day 11; adapted, with permission, from [51]. (j1) Bioprinted vascular tissue constructs using a co-axial nozzle apparatus, where (j2) loaded HUVSMCs generated smooth muscle matrix under 6-week differentiation media, particularly in the luminal and outer surface of the tissue constructs; adapted, with permission, from [98].

Figure 3. Bioprinted composite tissue constructs. (a1) A muscle-tendon unit frame made of PU (upperhalf) and polycaprolactone (PCL; lower-half) at a higher magnification view of (a2) printed PU filaments, (a2) filaments at the interface and (a3) printed PCL filaments; adapted, with permission, from [67]. (b1) Bioprinted fibrocartilage samples (b2,b3) patterned by selectively depositing human mesenchymal stem cell (hMSC)-laden methacrylated gelatin (Me-Gel) droplets loaded with either transforming growth factor (TGF)- $\beta 1$ or bone morphogenetic protein (BMP)-2. (b4) Bioprinted precursor gel droplets were photo-crosslinked and droplets were demonstrated using Rhodamine B (red) and Dextran-Alexa Fluor 488 (green); adapted, with permission, from [71].

Figure 4. (a) Laser-assisted bioprinting setup for in situ bone printing of n-HA particles into critical-size calvarium defects in mouse model. (b) Histology results of 3-month in vivo culture revealing new tissue formation (marked with star) as opposed to an empty defect. (c1) X-ray microtomography images of 
bone tissue formation (c1) in 1 week, (c2) 1 month and (c3) 3 months; adapted, with permission, from [51].

Figure 5. Bioprinted tissue models for drug testing and high-throughput screening. (a1) Bioprinted liver tissue model loaded into a perfusion chamber; adapted, with permission, from [83]. (a2) Where HepG2laden alginate filaments were patterned allowing media flow for drug testing; adapted, with permission, from [84]. (b1) A schematic showing inkjet-bioprinting of three-layer constructs, where agar and bacteria were bioprinted on a glass slide followed by printing of alginate and a blend of antibiotics and $\mathrm{CaCl}_{2}$, (b2) light-microscopy and (b3) fluorescence imaging of the bioprinted samples; adapted, with permission, from [85]. (c1) A $3 \times 3$ mm bioprinted liver tissue model for drug testing with (c2) hematoxylin and eosin stain showing parenchymal $(\mathrm{P})$ and nonparenchymal $(\mathrm{N})$ regions (image courtesy of Organovo).

Figure 6. Bioprinted tissue models for cancer research. Cervical tumor model: (a) phase-contrast images showing bioprinted HeLa cells forming spheroids within gelatin-alginate-fibrinogen on day 5, where spheroids got larger with further aggregation and proliferation of cells on day 8; (b) immunofluorescence images showing f-actin and DAPI (nuclei) of the forming aggregates on days 5 and 8; adapted, with permission, from [92].

\section{Author biographies}

\section{Ibrahim Tarik Ozbolat}

Ibrahim Tarik Ozbolat is an Associate Professor in the Engineering Science and Mechanics Department and the Huck Institutes of the Life Sciences at Penn State University. He received his PhD from the University at Buffalo, New York, and dual BS degrees in mechanical and industrial engineering from Middle East Technical University, Turkey. Dr Ozbolat's major research effort is in the area of 3D bioprinting. He has published over 80 journal and conference articles, and his research has been 
featured in local, national and international media. He is the recipient of several prestigious international awards.

\section{Weijie Peng}

Weijie Peng received his PhD degree from the Department of Pharmacology, Central South University, China, in 2005. He is an Associate Professor in the Department of Pharmacology, Nanchang University, China. He has recently joined the Ozbolat Lab at Penn State University as a visiting scholar supported by the Chinese Scholarship Committee. His major research work is on estrogen receptor, estrogenic substances and bioprinting for pharmaceutical research.

\section{Veli Ozbolat}

Veli Ozbolat received his BS degree in mechanical engineering from the Middle East Technical University, Ankara, Turkey, in 2008; and his MS degree in industrial engineering from the University at Buffalo, New York, USA, in 2010. He obtained his PhD in mechanical engineering from Cukurova University, Adana, Turkey, in 2015. He will join Penn State University as a postdoctoral scholar in Summer 2016. His research mainly focuses on biomedical engineering, heat transfer and fluid mechanics. 
Tissue Engineering and Regenerative Medicine
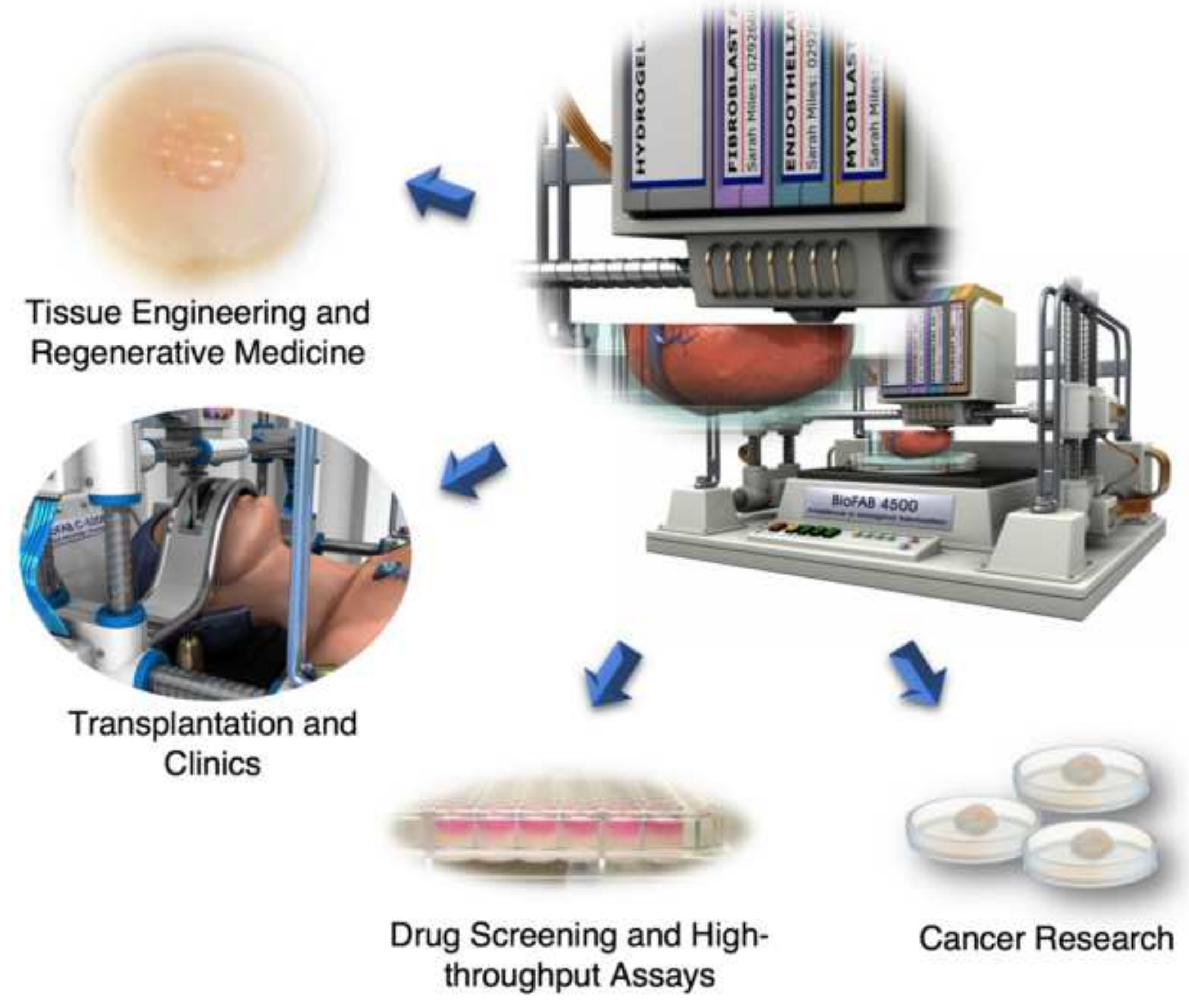
Clinics

Drug Screening and Highthroughput Assays
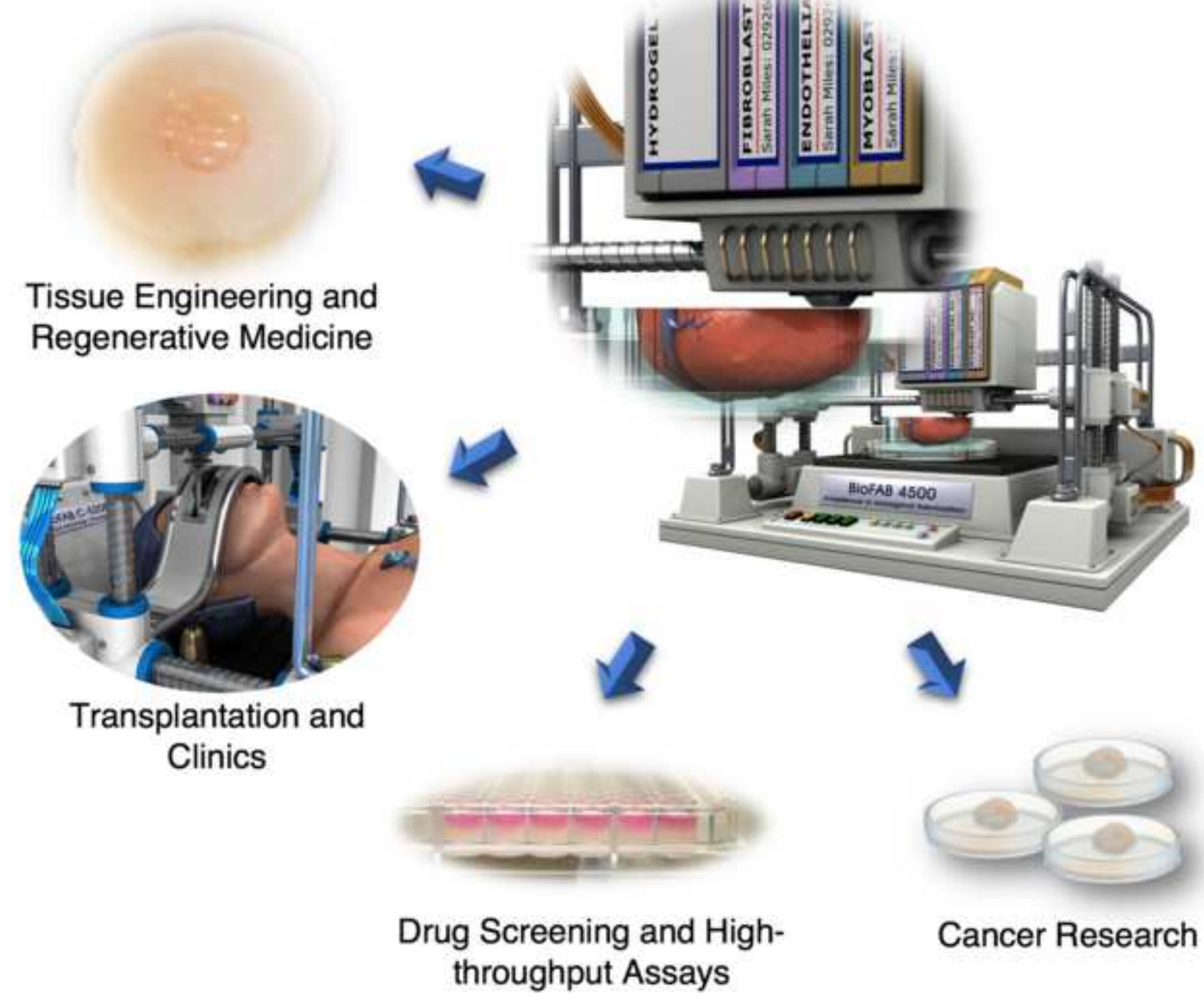

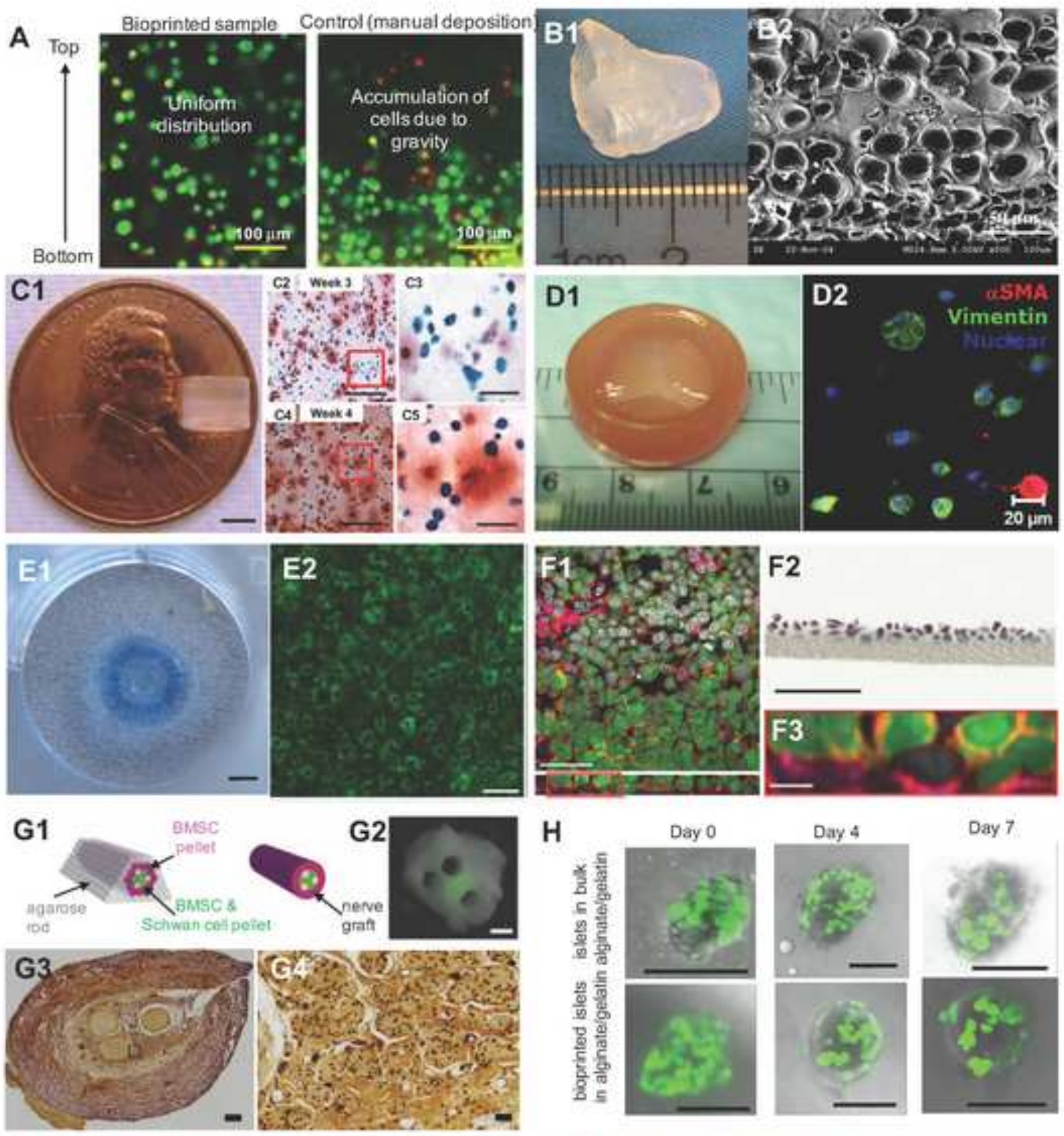

H

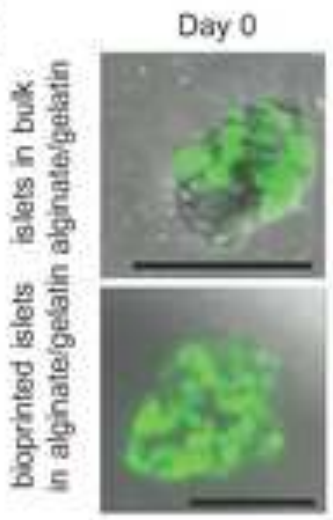

Day 4
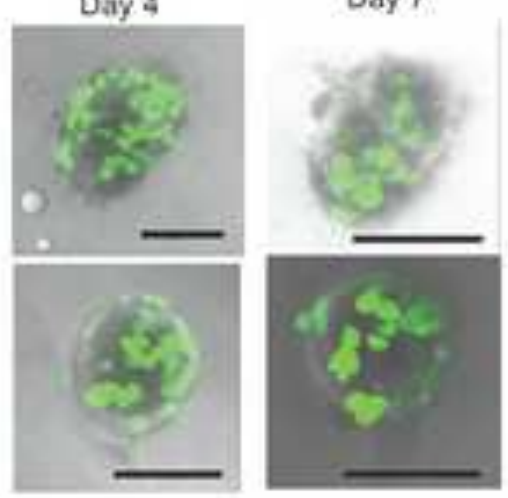
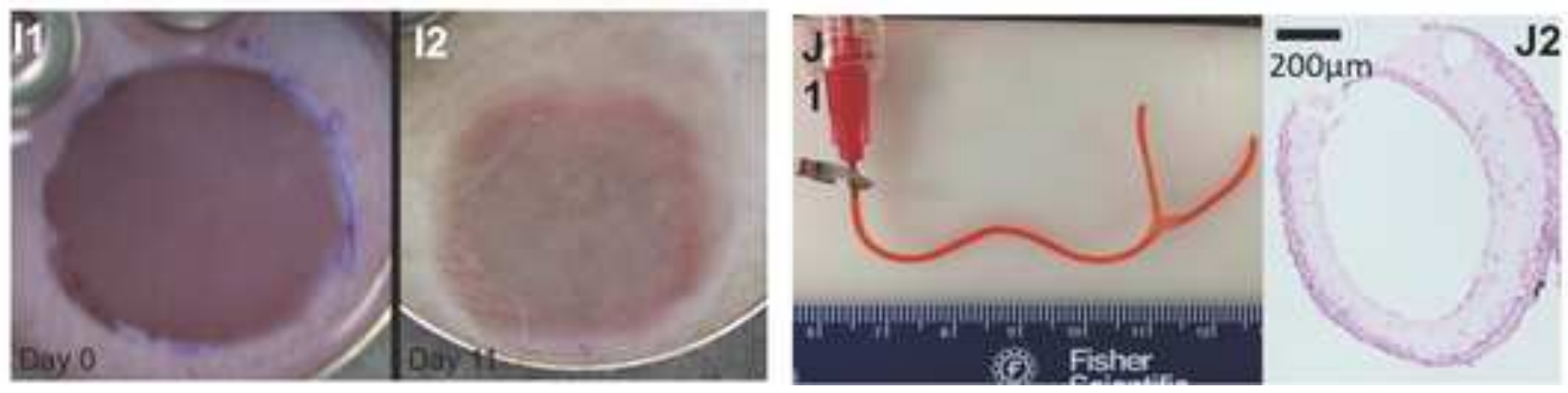

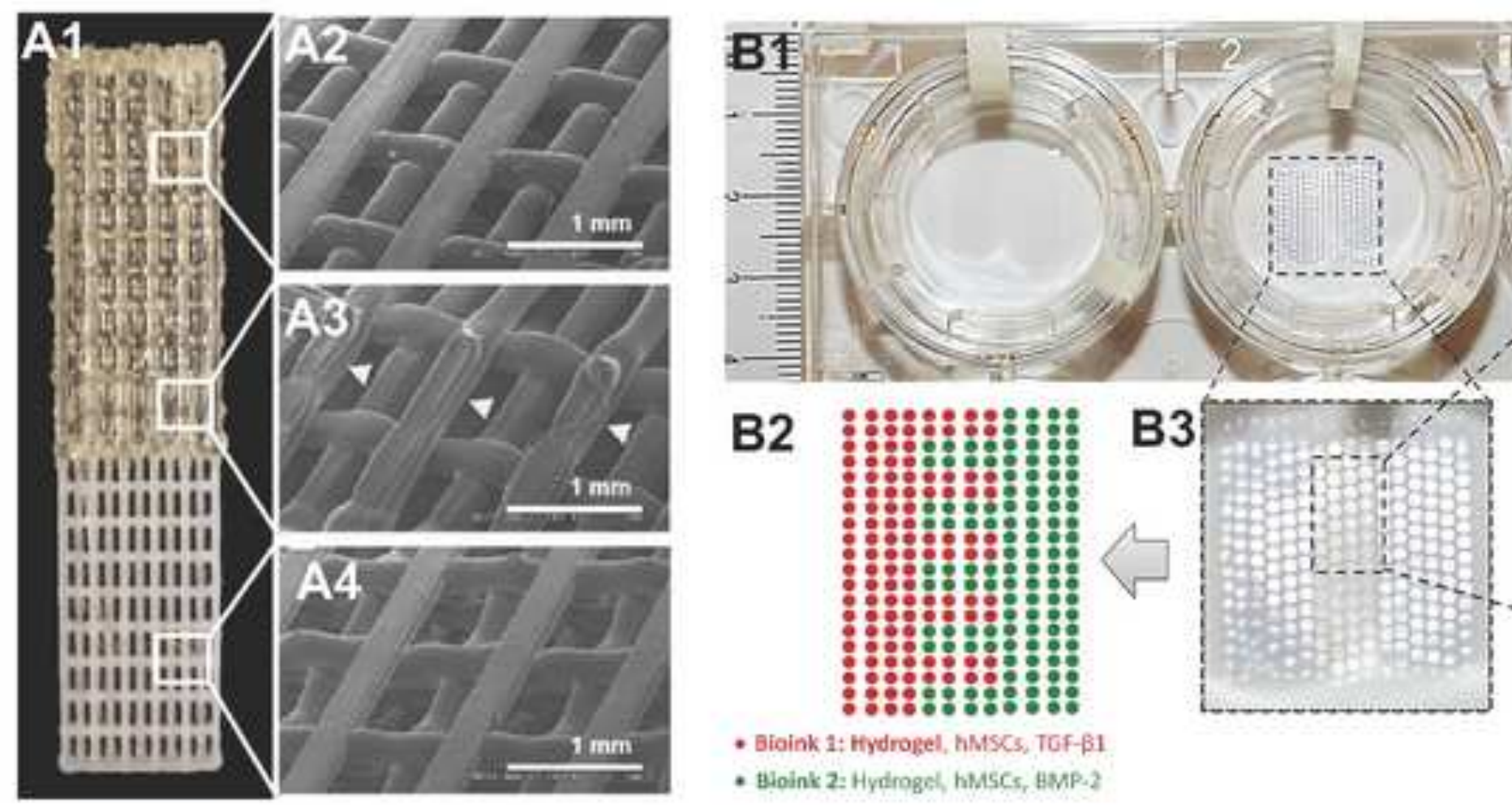

B400 jóó OOOO $000 \mathrm{C}$ Do 00 000 O00. 000 बढ் बि०० - 000 d.,

- Bloink 1: Hydrogel, hM MCs, TOF- $\beta 1$

- Bloink 2: Hydrogel, hMSCs, BMP.? 

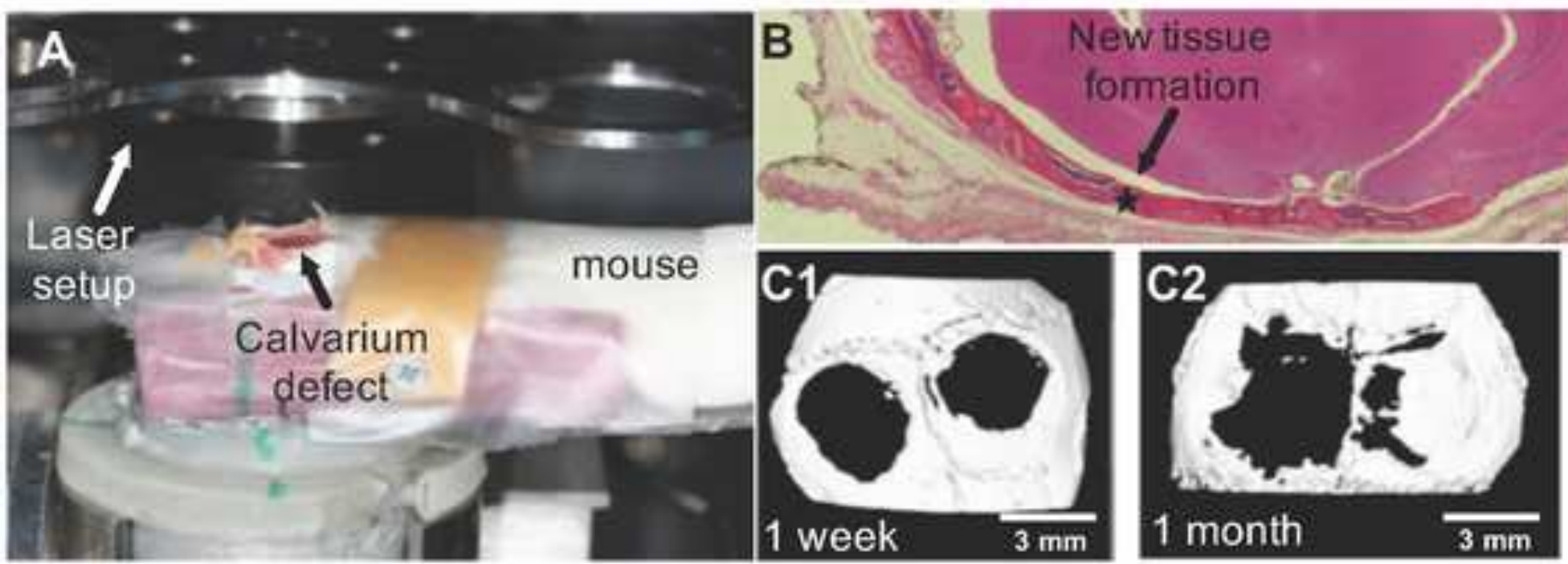

Open defect (control) $1000 \mu \mathrm{m}$

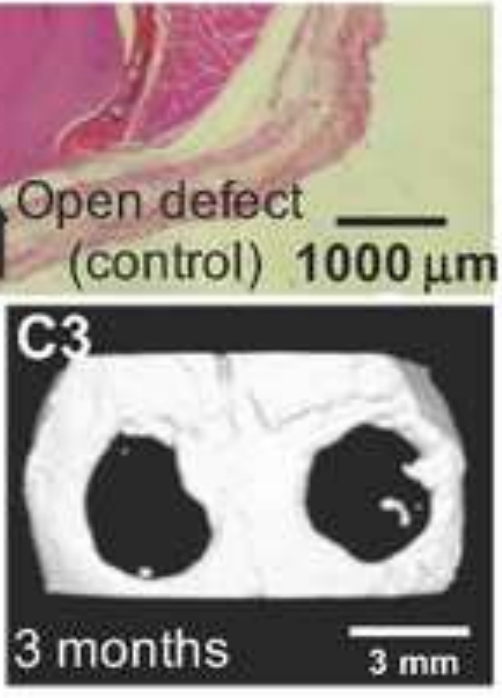

mont 

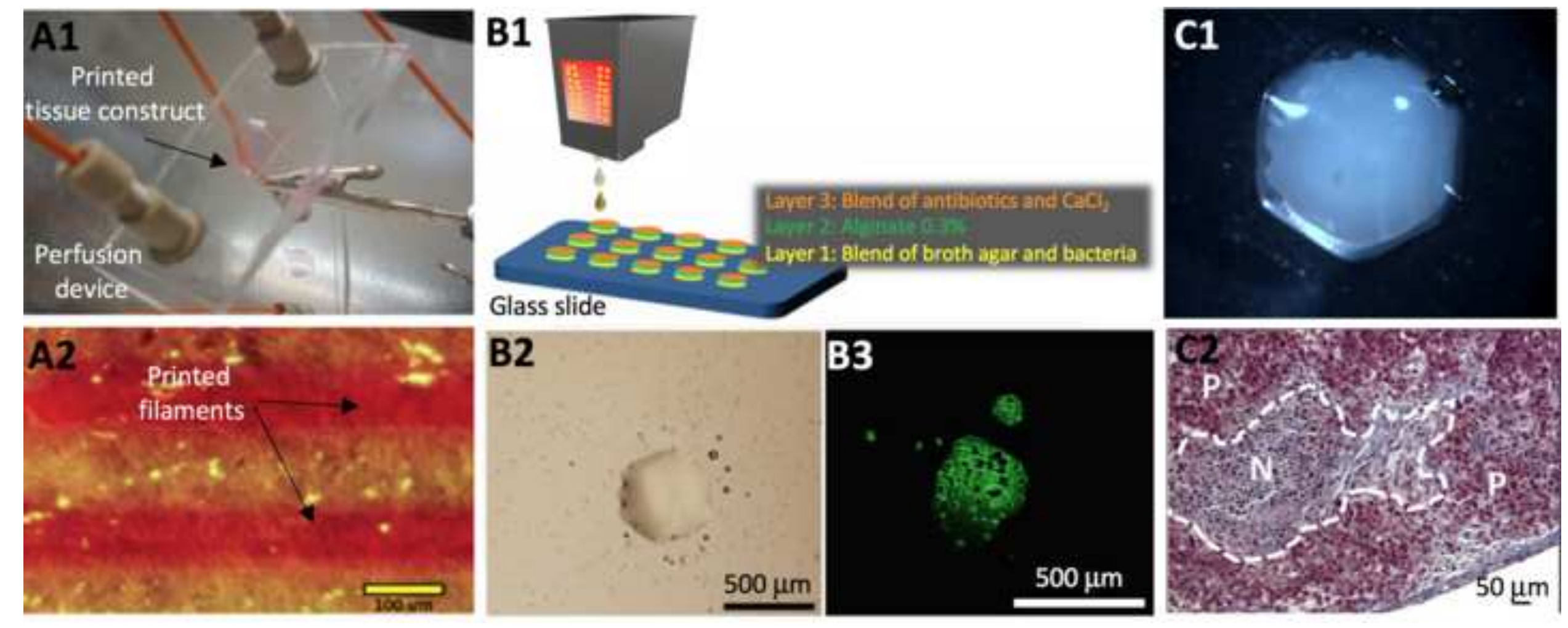


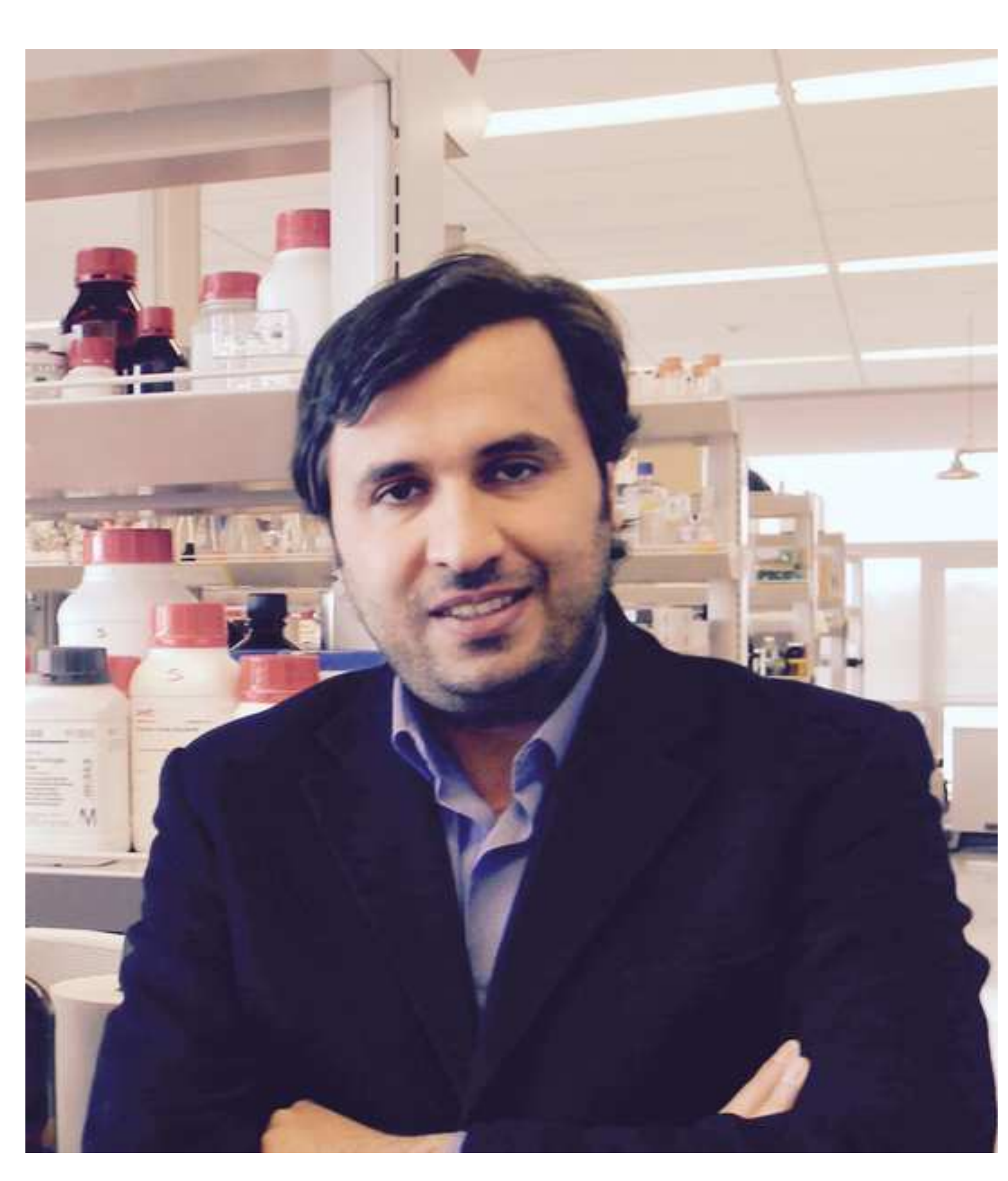

.
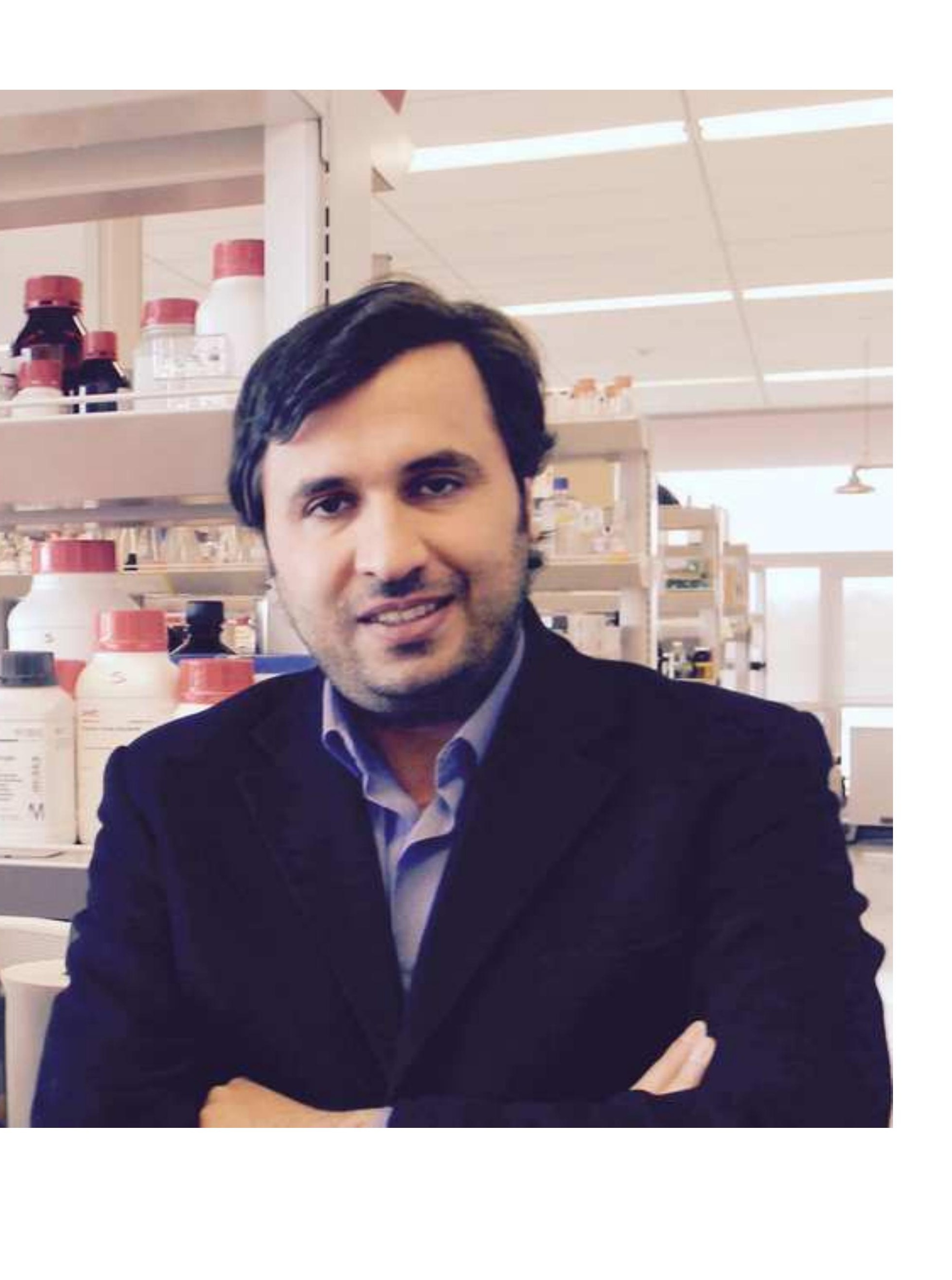

.

rar

.
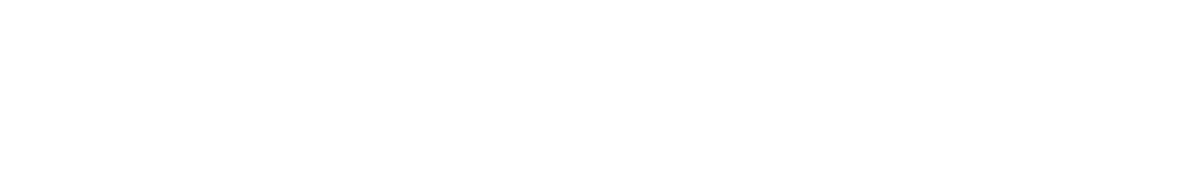

( 


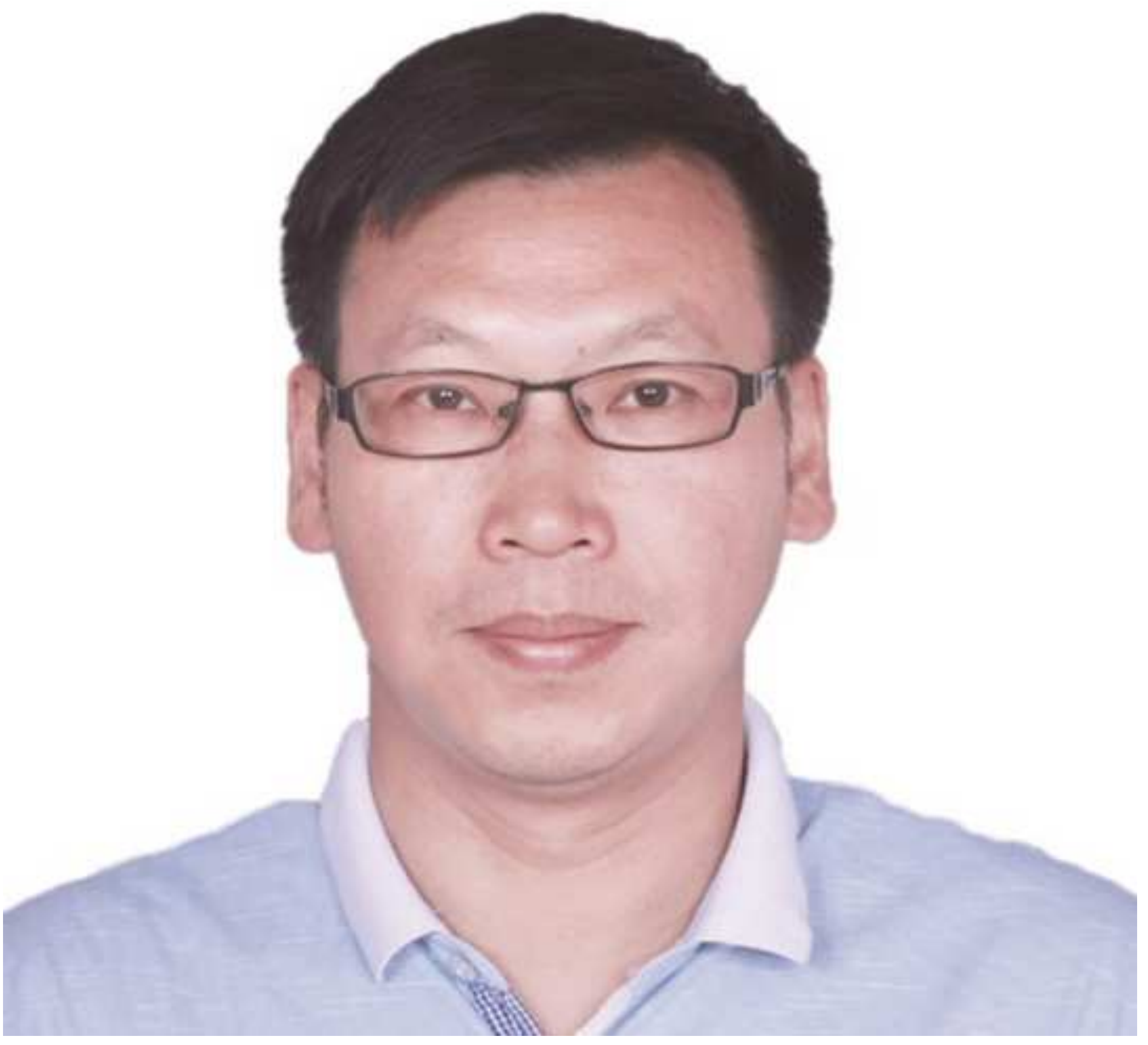

Weijie Peng 


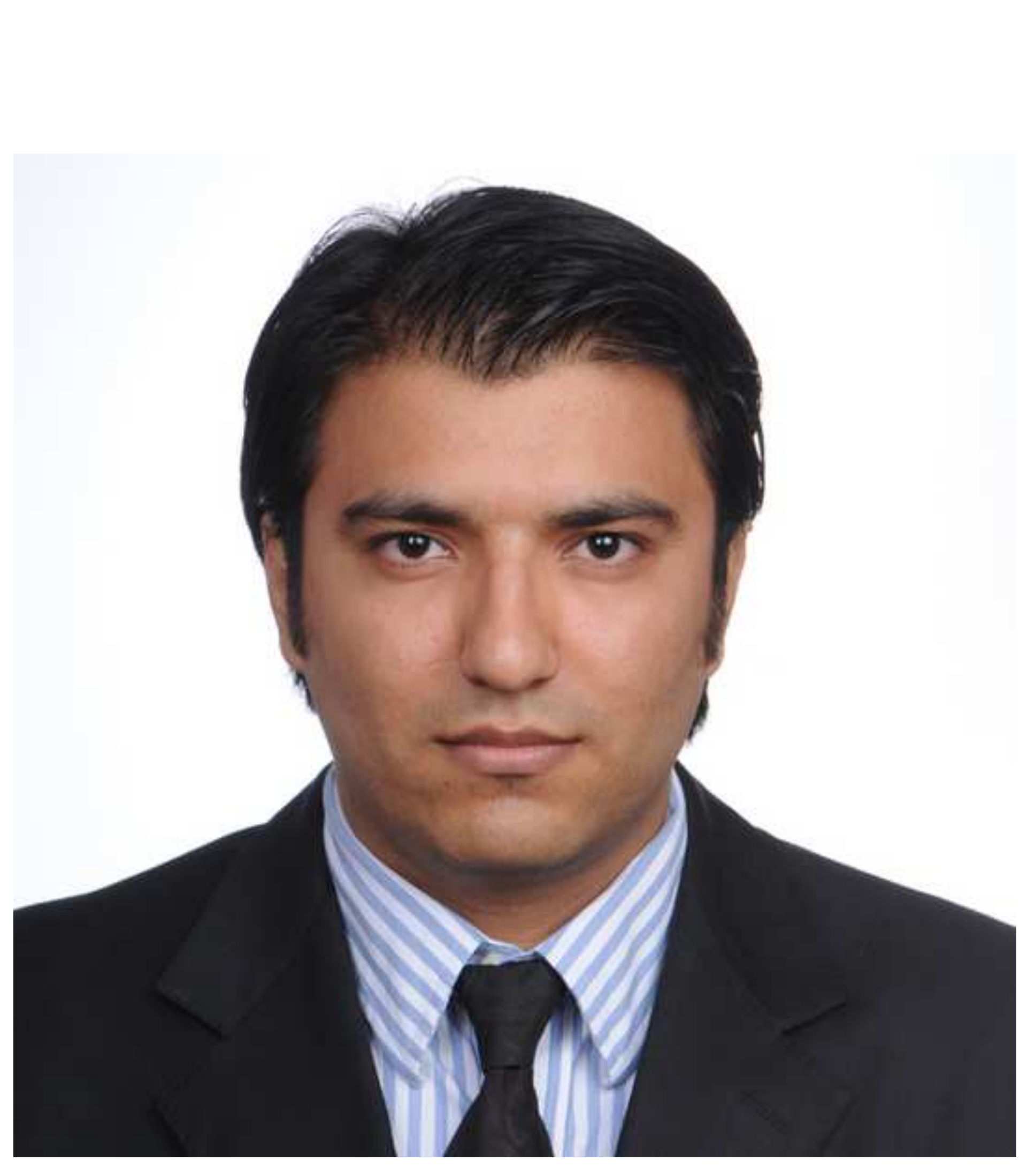

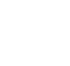

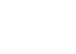

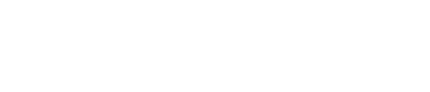

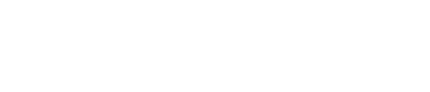

的

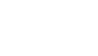

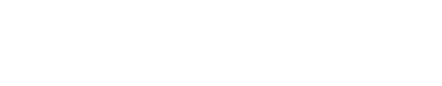

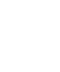

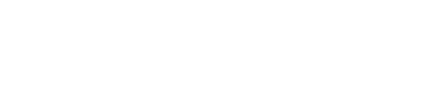

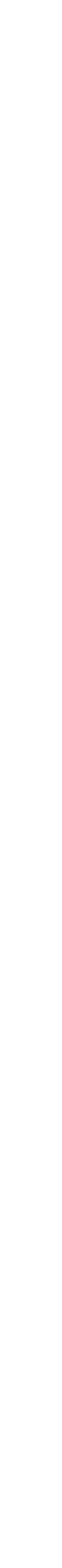


Table 1. Applications of bioprinting technologies

\begin{tabular}{|c|c|c|c|c|c|c|}
\hline Application & $\begin{array}{l}\text { Tissue } \\
\text { type }\end{array}$ & Cell types bioprinted & $\begin{array}{c}\text { Bioink or substrate } \\
\text { used }\end{array}$ & $\begin{array}{c}\text { Bioprinting modalities } \\
\text { used }\end{array}$ & $\begin{array}{c}\text { Bioprinters } \\
\text { used }\end{array}$ & Remarks \\
\hline \multirow{5}{*}{ 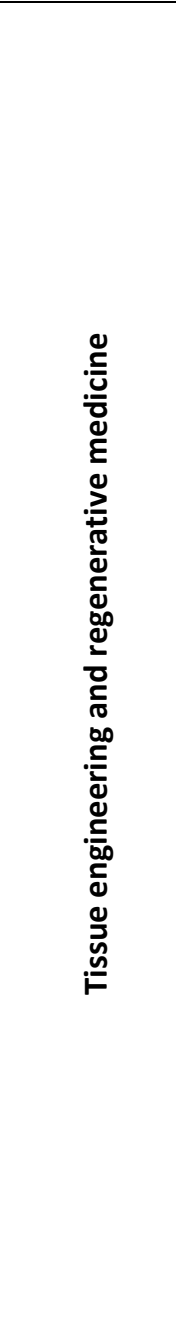 } & $\begin{array}{l}\Perp \\
\check{D} \\
\varnothing\end{array}$ & $\begin{array}{c}\text { Bone-marrow-derived human } \\
\text { mesenchymal stem cells [10]; } \\
\text { endothelial progenitor and } \\
\text { multipotent stromal cells [12]; } \\
\text { primary-muscle-derived stem } \\
\text { cells [13] }\end{array}$ & $\begin{array}{c}\text { PEGDMA [10]; nano- } \\
\text { HA slurry [11]; } \\
\text { Matrigel }{ }^{\mathrm{TM}} \text { and } \\
\text { alginate [12]; BMP2 } \\
\text { and fibrin (substrate) } \\
{[13]}\end{array}$ & $\begin{array}{l}\text { Thermal inkjet [10]; } \\
\text { laser-induced droplet } \\
\text { ejection [11]; extrusion- } \\
\text { based (pneumatic) [12]; } \\
\text { piezoelectric drop-on- } \\
\text { demand [13] }\end{array}$ & $\begin{array}{l}\text { Hewlett-Packard } \\
\text { deskjet [10]; HT- } \\
\text { BioLP } \\
\text { workstation [11]; } \\
\text { Bioplotter [12]; } \\
\text { MicroJet }^{\mathrm{TM}}[13]\end{array}$ & $\begin{array}{l}\text { Bioprinting bone tissue for } \\
\text { critical-size defects is } \\
\text { currently feasible but } \\
\text { bioprinting of scale-up } \\
\text { vascularized bone tissues } \\
\text { still remains elusive }\end{array}$ \\
\hline & $\frac{.0}{\frac{.0}{0}}$ & $\begin{array}{c}\text { Cardiac cells and HUVECs [16]; } \\
\text { primary feline adult } \\
\text { cardiomyoctyes and HL1 cardiac } \\
\text { muscle cells [17]; HUVEC and } \\
\text { hMSC [18]; human cardiac- } \\
\text { derived cardiomyocytes } \\
\text { progenitor cells [19] }\end{array}$ & $\begin{array}{c}\text { Tissue spheroids and } \\
\text { collagen type-I } \\
\text { (biopaper) [16]; } \\
\text { alginate [17,19]; PU } \\
{[18]}\end{array}$ & $\begin{array}{c}\text { Extrusion-based } \\
\text { bioprinting (mechanical) } \\
{[16,19] ; \text { thermal inkjet }} \\
\text { [17]; LIFT [18] }\end{array}$ & $\begin{array}{l}\text { nScrypt [16]; HP } \\
\text { DeskJet 550 } \\
\text { printers [17]; } \\
\text { custom laser } \\
\text { bioprinter [18]; } \\
\text { BioScaffolder } \\
\text { [19] }\end{array}$ & $\begin{array}{c}\text { Because cardiac cells do not } \\
\text { have proliferation } \\
\text { capability, scaffold-free } \\
\text { bioprinting with high cell } \\
\text { density is advantageous }\end{array}$ \\
\hline & 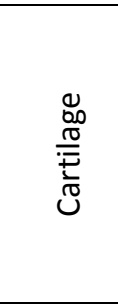 & $\begin{array}{l}\text { Human chondrocytes [22]; } \\
\text { rabbit elastic chondrocytes [24]; } \\
\text { bovine articular chondrocytes } \\
\text { [25]; calve articular } \\
\text { chondrocytes [26]; human } \\
\text { nasoseptal chondrocytes [27] }\end{array}$ & $\begin{array}{l}\text { PEGDMA [22]; fibrin- } \\
\text { collagen type I [24]; } \\
\text { alginate }[25,26] ; \\
\text { alginate/nano- } \\
\text { cellulose }[27]\end{array}$ & $\begin{array}{l}\text { Thermal inkjet [22]; } \\
\text { solenoid inkjet [24]; } \\
\text { extrusion-based } \\
\text { (pneumatic) [25]; } \\
\text { extrusion-based (micro- } \\
\text { valve) [27]; extrusion- } \\
\text { based (mechanical) [26] }\end{array}$ & $\begin{array}{l}\text { HP Deskjet } 500 \\
\text { printer [22]; XYZ } \\
\text { plotter [24]; } \\
\text { MABP [25]; Fab } \\
\text { @ home [26]; } \\
\text { regenHU [27] }\end{array}$ & $\begin{array}{c}\text { Considerable work has been } \\
\text { performed; however, } \\
\text { zonally stratified articular } \\
\text { cartilage is still a challenge } \\
\text { and a great need in clinical } \\
\text { use }\end{array}$ \\
\hline & $\begin{array}{l}\frac{0}{\pi} \\
\frac{2}{2} \\
\frac{1}{10} \\
\frac{1}{1}\end{array}$ & $\begin{array}{l}\text { Aortic root sinus smooth muscle } \\
\text { cells and aortic valve interstitial } \\
\text { cells [32]; aortic valvular } \\
\text { interstitial cells [33] }\end{array}$ & $\begin{array}{l}\text { PEGDA and alginate } \\
\text { [30]; alginate and } \\
\text { gelatin [32]; Me-Gel } \\
\text { [33] }\end{array}$ & $\begin{array}{c}\text { Extrusion-based } \\
\text { (mechanical) }[30,32,33]\end{array}$ & $\begin{array}{c}\text { Fab @ home } \\
{[30,32,33]}\end{array}$ & $\begin{array}{l}\text { Although anatomically } \\
\text { accurate tissue models have } \\
\text { been bioprinted, no } \\
\text { performance evaluation has } \\
\text { been done in vivo }\end{array}$ \\
\hline & $\stackrel{\grave{\Phi}}{\stackrel{亠}{\Xi}}$ & $\begin{array}{l}\text { hiPSCs and human embryonic } \\
\text { stem cells [35]; HepG2 [36] }\end{array}$ & $\begin{array}{c}\text { Alginate [35]; GelMA } \\
\text { [36] }\end{array}$ & $\begin{array}{c}\text { Valve-based inkjet [35]; } \\
\text { extrusion-based } \\
\text { (mechanical) [36] }\end{array}$ & $\begin{array}{c}\text { Custom cell } \\
\text { printer [35]; } \\
\text { NovoGen } \mathrm{MMX} \\
\text { Bioprinter }^{\mathrm{TM}}[36]\end{array}$ & $\begin{array}{l}\text { Limited progress has been } \\
\text { made in bioprinting of liver } \\
\text { tissues for regenerative } \\
\text { medicine, and patient- } \\
\text { specific cells with long-term } \\
\text { viability is still a concern }\end{array}$ \\
\hline
\end{tabular}




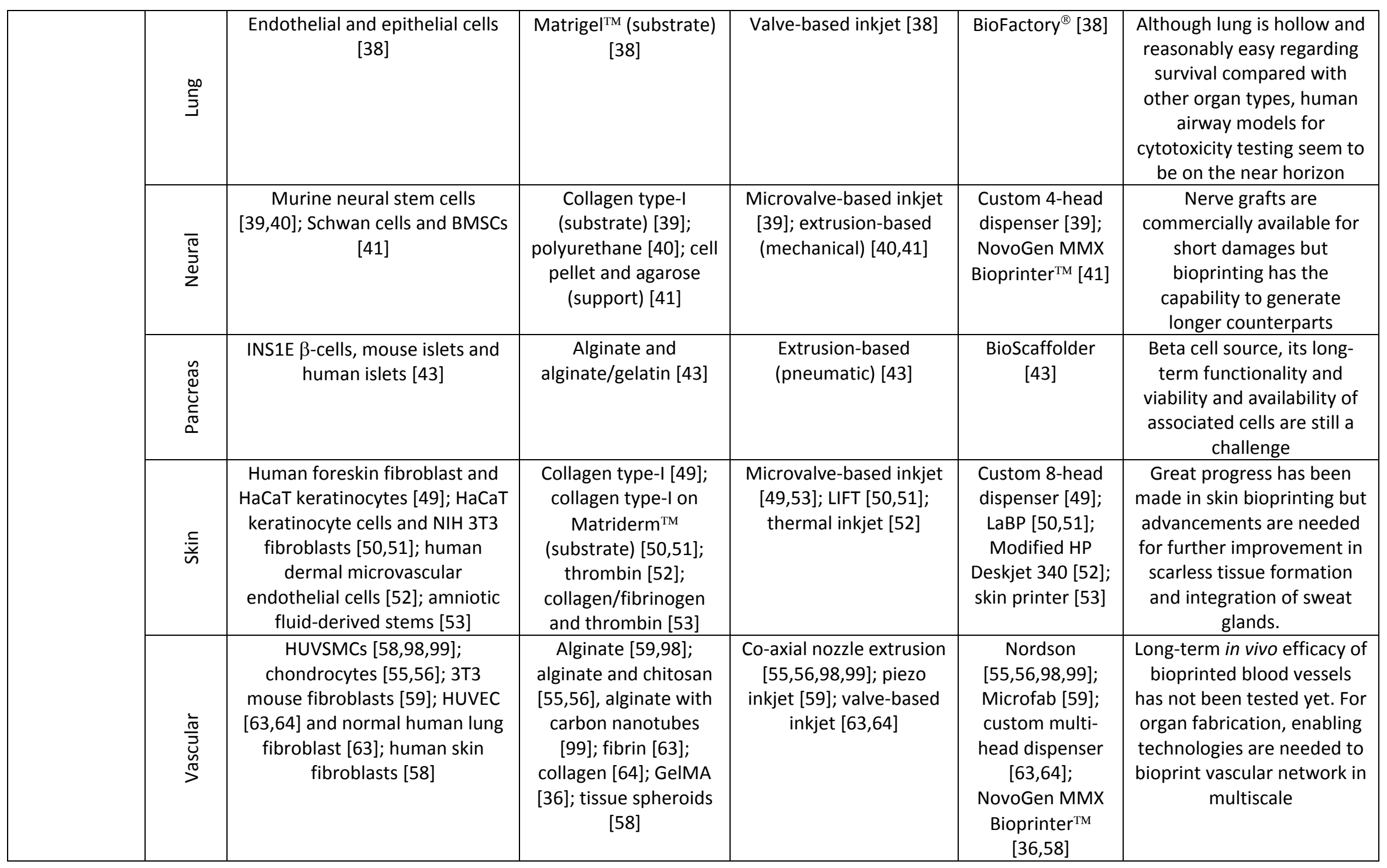




\begin{tabular}{|c|c|c|c|c|c|c|}
\hline & 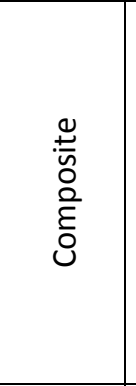 & $\begin{array}{l}\text { 3T3 fibroblasts and myoblasts } \\
\text { [67]; MSCs [68,81] and } \\
\text { chondrocytes [68]; osteoblast } \\
\text { and chondrocytes [69,70]; } \\
\text { HUVSMCs and fibroblasts [72] }\end{array}$ & $\begin{array}{c}\text { Hyaluronic } \\
\text { acid/gelatin/fibrinoge } \\
\mathrm{n} \text { and PU [67]; alginate } \\
\text { [68,70,72]; collagen } \\
\text { type I and hyaluronic } \\
\text { acid [69]; tissue } \\
\text { strands [72] }\end{array}$ & $\begin{array}{c}\text { Extrusion-based } \\
\text { (pneumatic) }[67-70,72] ; \\
\text { acoustic-based droplet } \\
{[81]}\end{array}$ & $\begin{array}{l}\text { Custom multi- } \\
\text { nozzle head } \\
{[67,68,81] ;} \\
\text { MtoBS }[69,70] ; \\
\text { MABP }[72]\end{array}$ & $\begin{array}{l}\text { Bioprinting of composite } \\
\text { tissues is highly vital and a } \\
\text { substantial progress is } \\
\text { needed to generate organ- } \\
\text { level constructs by } \\
\text { integrating tissues such as } \\
\text { bone, muscle, tendon, } \\
\text { nerve, blood vessels and } \\
\text { skin together }\end{array}$ \\
\hline \multirow{2}{*}{ 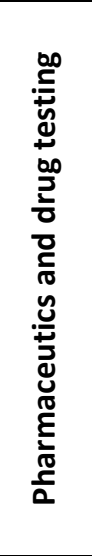 } & 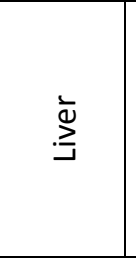 & $\begin{array}{l}\text { HepG2 [82,83]; epithelial cells } \\
\text { and hepatocytes [5]; human } \\
\text { hepatocytes, hepatic satellite } \\
\text { cells and endothelial cells [90] }\end{array}$ & $\begin{array}{l}\text { Alginate }[82,83] ; \\
\text { Matrigel }^{\mathrm{TM}}[5] ; \text { cell } \\
\text { pellet }[90]\end{array}$ & $\begin{array}{c}\text { Extrusion-based (valve) } \\
{[5,82,83] ; \text { extrusion- }} \\
\text { based (mechanical) [90] }\end{array}$ & $\begin{array}{c}\text { Multi-nozzle } \\
\text { system'[5,82,83]; } \\
\text { NovoGen MMX } \\
\text { Bioprinter }{ }^{\mathrm{TM}}[90]\end{array}$ & $\begin{array}{l}\text { Bioprinted liver tissue } \\
\text { models have a great } \\
\text { potential in early drug } \\
\text { discovery but a standard } \\
\text { model is yet to be } \\
\text { developed }\end{array}$ \\
\hline & 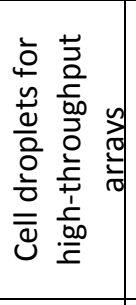 & $\begin{array}{l}\text { Escherichia coli [85]; primary } \\
\text { smooth muscle cells from rat } \\
\text { bladder [87]; mouse embryonic } \\
\text { stem cells, fibroblasts, AML-12 } \\
\text { hepatocytes, human Raji cells } \\
\text { and HL-1 cardiomyocytes [86] }\end{array}$ & $\begin{array}{l}\text { Alginate and soy agar } \\
\text { (substrate) [85]; } \\
\text { collagen [87]; sucrose } \\
\text { and dextrose [86] }\end{array}$ & $\begin{array}{l}\text { Thermal inkjet }[85] \\
\text { acoustic-based }[86,87]\end{array}$ & $\begin{array}{l}\text { Modified-HP } \\
\text { [85]; a custom } \\
\text { acoustic } \\
\text { bioprinter } \\
{[86,87]}\end{array}$ & $\begin{array}{l}\text { Picoliter size of droplets can } \\
\text { be generated with high } \\
\text { accuracy in droplet size and } \\
\text { location, which is highly } \\
\text { efficient for high- } \\
\text { throughput arrays for drug } \\
\text { testing }\end{array}$ \\
\hline 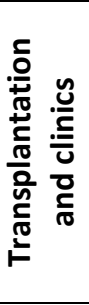 & 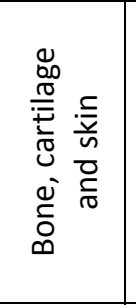 & $\begin{array}{l}\text { AFS and bone-marrow-derived } \\
\text { MSCs [53]; bone marrow stem } \\
\text { cells [1] }\end{array}$ & $\begin{array}{l}\text { PCL [77]; nHA [11]; } \\
\text { collagen-fibrin [53]; } \\
\text { alginate and } \\
\text { Pluronic }{ }^{\circledR} \text {-collagen [1] }\end{array}$ & $\begin{array}{l}\text { Laser-based printing } \\
\text { [77]; laser-based } \\
\text { bioprinting [11]; piezo- } \\
\text { inkjet [53]; extrusion } \\
\text { (pneumatic) [1] }\end{array}$ & $\begin{array}{c}\text { EOS P } 100 \\
\text { Formiga system } \\
\text { [77]; HT-BioLP } \\
\text { workstation [11]; } \\
\text { custom inkjet } \\
\text { printer [53]; } \\
\text { MABP [1] }\end{array}$ & $\begin{array}{l}\text { Only transplantation of a } \\
\text { splint (using a non- } \\
\text { bioprinting technique) into } \\
\text { a human and in situ } \\
\text { bioprinting on animal } \\
\text { models has been achieved } \\
\text { in operating rooms }\end{array}$ \\
\hline 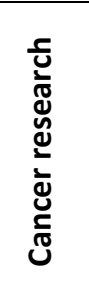 & 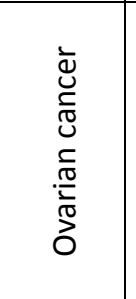 & $\begin{array}{l}\text { Human ovarian cancer cells and } \\
\text { MRC-5 fibroblasts [91] }\end{array}$ & $\begin{array}{c}\text { Matrigel }^{\mathrm{TM}} \text { (substrate) } \\
{[91]}\end{array}$ & $\begin{array}{l}\text { Solenoid-valve ejection } \\
\text { [91] }\end{array}$ & $\begin{array}{l}\text { A custom dual- } \\
\text { head bioprinter } \\
{[91]}\end{array}$ & $\begin{array}{c}\text { Only a technological } \\
\text { platform has been } \\
\text { demonstrated so far but } \\
\text { bioprinting of a } \\
\text { biomimetically developed } \\
\text { ovarian cancer model is yet } \\
\text { to be researched }\end{array}$ \\
\hline
\end{tabular}




\begin{tabular}{|c|c|c|c|c|c|c|}
\hline & 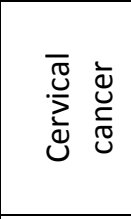 & $\begin{array}{c}\text { HeLa }[92,93] ; 10 \mathrm{~T} 1 / 2 \text { fibroblasts } \\
{[93]}\end{array}$ & $\begin{array}{l}\text { Gelatin/alginate/fibrin } \\
\text { ogen [92]; PEGDA [93] }\end{array}$ & $\begin{array}{c}\text { Extrusion-based } \\
\text { (mechanical) [92] and } \\
\text { laser-based projection } \\
\text { printing [93] }\end{array}$ & $\begin{array}{l}\text { Cell assembly } \\
\text { system I [92]; } \\
\text { DMD-PP [93] }\end{array}$ & $\begin{array}{l}\text { Only a very few attempts, at } \\
\text { the basic research level, } \\
\text { have been made for } \\
\text { bioprinting of cervical } \\
\text { cancer models }\end{array}$ \\
\hline & 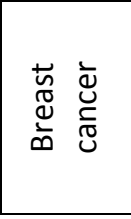 & $\begin{array}{l}\text { MSC differentiated adipose } \\
\text { cells, mammary fibroblasts and } \\
\text { endothelial cells [94] }\end{array}$ & Cell pellet [94] & $\begin{array}{l}\text { Extrusion-based } \\
\text { (mechanical) [94] }\end{array}$ & $\begin{array}{l}\text { NovoGen MMX } \\
\text { Bioprinter }{ }^{\mathrm{TM}}[94]\end{array}$ & $\begin{array}{l}\text { Further substantial } \\
\text { development is needed to } \\
\text { use the bioprinted breast } \\
\text { cancer model for cancer } \\
\text { screening and drug testing }\end{array}$ \\
\hline
\end{tabular}

Abbreviations: PEGDMA, poly(ethylene glycol) dimethacrylate; HUVECs, human vascular endothelial cells; 